Check for updates

Cite this: Med. Chem. Commun., 2018, 9, 282

Received 16th September 2017, Accepted 11th December 2017

DOI: $10.1039 / \mathrm{c} 7 \mathrm{md} 00472 a$

rsc.li/medchemcomm

\section{Synthesis, characterization and biological application of 5-quinoline 1,3,5-trisubstituted pyrazole based platinum(॥) complexes $\uparrow$}

\author{
Miral V. Lunagariya, ${ }^{a}$ Khyati P. Thakor, ${ }^{a}$ Reena R. Varma, ${ }^{a}$ Bhargav N. Waghela, ${ }^{b}$ \\ Chandramani Pathak ${ }^{\mathrm{b}}{ }^{\mathrm{b}}$ and Mohan N. Patel iD *a
}

\begin{abstract}
Square planar mononuclear platinum(II) complexes were synthesized in the presence of neutral bidentate heterocyclic (5-quinoline 1,3,5-tri-substituted pyrazole scaffold) ligands and $\mathrm{K}_{2} \mathrm{PtCl}_{4}$ salt. The synthesized compounds were characterized by micro-elemental analysis, FT-IR, UV-vis, ${ }^{1} \mathrm{H} N M R,{ }^{13} \mathrm{C} N M R, T G A$, mass spectrometry and molar conductivity. Their biological activities were investigated by in vitro brine shrimp lethality bioassay, in vitro antimicrobial study against five different pathogens, in vivo cellular level cytotoxicity against Schizosaccharomyces pombe cells, and in vitro anti-proliferation assay. The binding constant $K_{\mathrm{sv}}, K_{\mathrm{b}}, K_{\mathrm{a}}$ values of the complexes were determined by DNA interaction studies. The gel electrophoresis assay was carried out to examine the effect of the complexes on the DNA nuclease of pUC19 plasmid DNA. The docking energies of the ligands $\left(\mathrm{L}^{1}-\mathrm{L}^{5}\right)$ and complexes $(I-V)$ were observed in the range of -265.14 to $-284.33 \mathrm{~kJ} \mathrm{~mol}^{-1}$. The synthesized Pt(I) complexes (I-V) were screened against the MCF-7 (human breast adenocarcinoma) and HCT-116 (human colon carcinoma) cancer cell lines.
\end{abstract}

\section{Introduction}

In bioinorganic chemistry, metal complexes have been used for the treatment of many diseases such as cancer, arthritis, diabetes, and Alzheimer's. ${ }^{1,2}$ The development of platinum based anti-tumour drugs such as cisplatin, carboplatin, oxaliplatin and nedaplatin plays an intensely important role, and these drugs are used for the therapy of various types of cancer, such as germ cell tumours, ovarian, lung, head, neck, prostate, colon and bladder cancers. ${ }^{3,4}$ Cisplatin promotes cancer cell death by binding with DNA, and is one of the most used platinum anticancer drugs as well as effective antitumor agents. The effectiveness of drugs can be improved by (i) lowering the toxic side effects by decreasing their reactivity with non-DNA biological nucleophiles, (ii) the use of drug delivery vehicles to target clearly cancerous cells, leaving normal cells uninjured, (iii) increasing the efficiency of DNA binding inside the cell, and (iv) design of drugs that form novel adducts with DNA, different to those of cisplatin, which are still able to prevent DNA transcription and replication, but are not

\footnotetext{
${ }^{a}$ Department of Chemistry, Sardar Patel University, Vallabh Vidyanagar-388 120, Gujarat, India. E-mail: jeenen@gmail.com; Tel: (+912692) 226856218

${ }^{b}$ Department of Cell Biology, School of Biological Sciences and Biotechnology, Indian Institute of Advanced Research, Koba Institutional Area, Gandhinagar382007, Gujarat, India. Tel: +917930514245

$\dagger$ Electronic supplementary information (ESI) available. See DOI: 10.1039/ c7md00472a
}

recognised and removed by DNA repair proteins. ${ }^{5}$ On the basis of the structural equivalence (for $\mathrm{d}^{8}$ systems the squareplanar geometry is preferred) and thermodynamic variance of platinum(II) complexes, there is much interest in the study of platinum(II) complexes as potential anticancer drugs, especially with 5-quinoline based 1,3,5-tri-substituted pyrazole based ligands. ${ }^{6-10}$

Quinolines are heterocyclic aromatic organic compounds containing nitrogen atoms. Quinoline derivative compounds are generally used as "parental" compounds to synthesize molecules with medical benefits, mainly with anti-microbial and anti-malarial activities. ${ }^{11}$ These azo-heterocycles have considerable interest because a large number of natural products and drugs contain azo-heterocyclic units. Quinoline based drugs are used for pharmacological and various biological activities. ${ }^{6,12}$ Quinoline and its analogues have recently been examined for their modes of function in the inhibition of tyrosine kinases, proteasome, tubulin polymerization, topoisomerase and DNA repair. Uses of quinoline based compounds are fast spreading from anticancer drugs to almost every branch of medicinal chemistry. Quinoline derivatives exhibit cytotoxicity through DNA intercalation, causing interference in the replication process. ${ }^{7,13}$ Pyrazoles are a large family of compounds that are widely used in various applications like agrochemicals and medicine, due to their broad range of biological activities. The azole (pyrazole) type drugs fluconazole, itraconazole, voriconazole, and posaconazole are significant for the treatment of invasive fungal infections 
(IFIs). ${ }^{8}$ Most azoles are active, show a broad-spectrum against most filamentous fungi, and are relatively nontoxic..$^{1,14,15}$

In this paper, we have focused on the following points: (a) synthesis of substituted quinoline based ligands $\left(\mathbf{L}^{1}-\mathbf{L}^{5}\right)$ by three step reactions employing conventional methods, (b) synthesis of platinum(II) complexes (I-V) by single step onepot two-component reactions and (c) in the framework of biological significance, we have developed a new approach for structural diversity of heterocycles incorporated in scaffolds. The modifications made on pyrazole centres for probing antibacterial and anti-proliferation activity include: phenyl ring at $\mathrm{N}-1$ position, substituted thiophene ring at C-3 position and quinoline ring at $\mathrm{C}-5$ position. All synthesized compounds were evaluated for their biological activity including DNA binding studies, DNA nuclease, antibacterial activity, in vitro anti-proliferation studies, in vivo cytotoxicity against Schizosaccharomyces pombe at the cellular level and brine shrimp lethality bioassay against Artemia cyst.

\section{Experimental}

\section{Chemical reagents and materials}

All the chemicals used were of analytical grade. Potassium tetrachloro platinate(II) salt, 5-chloro-2-acetylthiophene, 5-bromo-2-acetylthiophene, 3-bromo-2-acetylthiophene, 4-methyl-2-acetylthiophene, and phenyl hydrazine hydride were purchased from Sigma Chemical Co. (India). Ethidium bromide (EB), bromophenol blue, agarose and Luria Broth (LB) were purchased from Hi-media Laboratories Pvt. Ltd., India. Cultures of pUC19 bacteria (MTCC 47), including two Gram(+ve) species, i.e. Staphylococcus aureus (S. aureus) (MTCC-3160) and Bacillus subtilis (B. subtilis) (MTCC-7193), and three $\operatorname{Gram}^{(-\mathrm{ve})}$ species, i.e. Serratia marcescens (S. marcescens) (MTCC-7103), Pseudomonas aeruginosa (P. aeruginosa) (MTCC-1688) and Escherichia coli (E. coli) (MTCC433), were purchased from Institute of Microbial Technology (Chandigarh, India). Ethidium bromide (EB) and pUC19 bacteria (MTCC 47) were used for all DNA binding and cleavage studies. S. pombe Var. Paul Linder 3360 was obtained from IMTECH, Chandigarh, India. Human colorectal carcinoma (HCT 116) and human breast adenocarcinoma (MCF-7) cell lines were obtained from National Center for Cell Science (NCCS), Pune, Maharashtra, India. HCT 116 cells were cultured in RPMI-1640 medium (Gibco, Life Technologies, USA) and MCF-7 cells were cultured in DMEM medium (Gibco, Life Technologies, USA). The culture media were supplemented with $10 \%$ fetal bovine serum (FBS) and PSN antibiotic solution (Gibco, Life Technologies, USA). The cells were kept in a humidified atmosphere of $5 \% \mathrm{CO}_{2}$ at $37{ }^{\circ} \mathrm{C}$. Exponentially growing cells were used for the entire study.

\section{Physical measurement}

The ${ }^{1} \mathrm{H}$ NMR and ${ }^{13} \mathrm{C}$ NMR spectra were recorded with a Bruker Avance (400 $\mathrm{MHz}$ and $100 \mathrm{MHz}$ ) either in $\mathrm{D}_{2} \mathrm{O}\left(25^{\circ} \mathrm{C}\right)$ or DMSO-d $\mathrm{d}_{6}\left(35^{\circ} \mathrm{C}\right)$, with TMS used as an internal reference. The following abbreviations apply to (used for) splitting pat- terns: s (singlet), d (doublet), t (triplet), q (quartet), $\mathrm{m}$ (multiplet). The chemical shift (parts per million) of each resonance is reported as the approximate midpoint of its multiplicity, $\delta$ (ppm) and the coupling constants $(J)$ in $\mathrm{Hz}$. The attached proton test in the ${ }^{13} \mathrm{C}$ NMR characterization showed $\mathrm{C}, \mathrm{CH}, \mathrm{CH}_{2}$ and $\mathrm{CH}_{3}$ signals for carbon attached to protons (below the base line being negative, above the base line being positive). Infrared spectra were recorded on an FTIR ABB Bomen MB-3000 spectrophotometer (Canada) in the range of 4000 to $400 \mathrm{~cm}^{-1}$. Micro elemental analysis (C, H, N and $\mathrm{S}$ ) of the synthesized compounds was performed with a model Euro EA elemental analyzer. Melting points $\left({ }^{\circ} \mathrm{C}\right.$, uncorrected) were determined in open capillaries on a thermoCal10 melting point apparatus (Analab Scientific Pvt. Ltd, India). The mass spectra were obtained on a Thermo Scientific mass spectrophotometer (USA), using the positive electrospray ionization mode. The electronic spectra were recorded on a UV-160A UV-vis spectrophotometer, Shimadzu, Kyoto (Japan). The magnetic moments were measured by Gouy's method using mercury tetrathiocyanatocobaltate(II) as the calibrant $\left(\chi_{\mathrm{g}}=16.44 \times 10^{-6} \mathrm{cgs}\right.$ units at $\left.20^{\circ} \mathrm{C}\right)$, Citizen balance. An antibacterial study was carried out using a laminar airflow cabinet (Toshiba, Delhi, India). The thermograms of the complexes were recorded with a Mettler Toledo TGA Thermogravimetric Analyzer. Fluorescence spectroscopy was carried out using a FluoroMax-4 spectrofluorometer, HORIBA (Scientific). Conductance measurement was carried out using a conductivity meter, model number E-660A. Photoquantization of the gel after electrophoresis was done using AlphaDigiDoc $^{\mathrm{TM}}$ Version V.4.0.0 PC-Image software, California (USA).

General procedure for the synthesis of 2-chloro-3formylquinolines via Vilsmeier-Haack reaction (2a)

2-Chloro-3-formylquinoline (2a) was prepared from $\mathrm{N}$-phenylacetamide via a Vilsmeier Haack reaction by using traditional methods. ${ }^{14}$ To a solution of $N$-phenylacetamide (1a) (1 mmol) in dry dimethyl formamide (DMF) $(3 \mathrm{mmol})$ at 0-5 ${ }^{\circ} \mathrm{C}$ with mechanical stirring, phosphoryl trichloride $\left(\mathrm{POCl}_{3}\right)(10 \mathrm{mmol})$ was added dropwise and charged in a 100 $\mathrm{mL}$ round bottom flask. After addition of these compounds, the reaction mixture was heated at $80-90{ }^{\circ} \mathrm{C}$ in a water bath for 2-3 h. After the completion of the reaction as confirmed by TLC, the reaction mixture was poured into $100 \mathrm{~mL}$ crushed ice-water, stirred for $10 \mathrm{~min}$ and the resulting reaction mass filtered, washed thoroughly with water and dried. The 2-chloro-3-formylquinoline (2a) product was purified and recrystallized from ethanol to obtain a pale yellow solid.

\section{Quinoline based thiophene derivative enones (4a-4e)}

Synthesis of $\alpha, \beta$ unsaturated carbonyl compounds was performed by Claisen-Schmidt condensation reaction. ${ }^{16}$ Methanolic solutions of different substituted 2-acetyl thiophenes $\left(-\mathrm{Cl},-\mathrm{Br},-\mathrm{CH}_{3},-\mathrm{H}\right)(3 \mathrm{a}-3 \mathrm{e})(\mathbf{\mathrm { mmol }})$ were prepared in round bottom flasks. To these, a methanolic solution of 
potassium hydroxide ( $\mathrm{KOH})$ was added dropwise, which acted to abstract acidic hydrogen from the 2-acetyl thiophene. Then, a methanolic solution of 2-chloro-3-formylquinoline was added dropwise to the reaction mixture. The reaction mixture was stirred at room temperature until formation of a precipitate. The obtained expected chalcone product was isolated by filtration, washed with cold ethanol and recrystallized from methanol.

\section{5-Quinoline based 1,3,5-trisubstituted pyrazole derivative} ligands $\left(\mathbf{L}^{\mathbf{1}}-\mathbf{L}^{\mathbf{5}}\right)$

The 2-chloro-3-(1-phenyl-3-(thiophen-2-yl)-1 $H$-pyrazol-5-yl) quinoline derivative enones $(\mathbf{4 a}-4 \mathrm{e})(1.0 \mathrm{mmol})$ and phenyl hydrazine (4a) $(1.0 \mathrm{mmol})$ were thoroughly mixed in ethanol (5 $\mathrm{mL})$ with potassium tertiary butoxide $\left(t-\mathrm{BuO}^{-} \mathrm{K}^{+}\right)(1 \mathrm{mmol})$ used to generate basic conditions in a $50 \mathrm{~mL}$ round bottom flask. The reaction mixture was refluxed for $5 \mathrm{~h}$. After the completion of the reaction was confirmed by a TLC ethyl acetate: hexane $(1: 5)$ system, the reaction mixture was cooled to room temperature, washed with water and dried over anhydrous $\mathrm{Na}_{2} \mathrm{SO}_{4}$. The ensuing product upon purification by chromatog- raphy (silica gel 60-120 mesh, eluent 20\% EtOAc/hexane) gave a yellowish solid as the desired product (Scheme 1).

Preparation of 2-chloro-3-(3-(5-chlorothiophen-2-yl)-1-phenyl$1 H$-pyrazol-5-yl) quinoline $\left(\mathrm{L}^{1}\right)$

The product $\mathbf{L}^{\mathbf{1}}$ was synthesized using phenyl hydrazine (4a) (0.389 g, $7 \mathrm{mmol})$ and different substituted quinoline derivative enones (3a-3e) $(1 \mathrm{~g}, 7 \mathrm{mmol})$ after reflux for $5 \mathrm{~h}$ in methanolic solution as described in general process. Colour: yellowish orange crystal, yield: $92 \%$, mol. wt: $424.34 \mathrm{~g} \mathrm{~mol}^{-1}$, m.p.: $270{ }^{\circ} \mathrm{C}$; anal. calc. (\%) for $\mathrm{C}_{22} \mathrm{H}_{15} \mathrm{Cl}_{2} \mathrm{~N}_{3} \mathrm{~S}$ : $\mathrm{C}, 62.77 ; \mathrm{H}, 3.10 ; \mathrm{N}, 9.95 ; \mathrm{S}, 7.59$. Found (\%): C, 63.08; H, 3.05; N, 10.20; S, 7.19. UV-vis: $\lambda(\mathrm{nm})\left(\varepsilon, \mathrm{M}^{-1} \mathrm{~cm}^{-1}\right): 261$ (38910), 307 (9440). Mass $m / z$ (\%): $423.25[\mathrm{M}]^{+} .{ }^{1} \mathrm{H}$ NMR (400 MHz, DMSO-d $\left.{ }_{6}\right) \delta /$ ppm: $3.284\left(1 \mathrm{H}, \mathrm{dd},{ }^{3} J_{1}=8.0 \mathrm{~Hz},{ }^{3} J_{2}=7.6\right.$ $\mathrm{Hz}, \mathrm{H}-\mathrm{a}), 4.119\left(1 \mathrm{H}, \mathrm{dd},{ }^{3} J_{1}=8.8 \mathrm{~Hz},{ }^{3} J_{2}=6.0 \mathrm{H}-\mathrm{b}\right), 5.739(1 \mathrm{H}$, $\left.\mathrm{dd},{ }^{3} J_{1}=10.4,{ }^{3} J_{2}=8.4 \mathrm{~Hz}, \mathrm{H}_{5}\right), 6.730-8.067(12 \mathrm{H}, \mathrm{m}$,

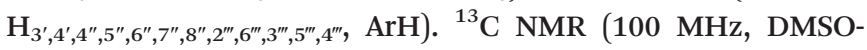
$\left.\mathrm{d}_{6}\right) \delta /$ ppm: $148.81\left(\mathrm{C}_{2^{\prime \prime}}, \mathrm{C}_{\text {quat. }}\right), 146.93$ ( $\left.\mathrm{C}_{9^{\prime \prime}}, \mathrm{C}_{\text {quat. }}\right), 144.73$ $\left(\mathrm{C}_{2^{\prime}}, \mathrm{C}_{\text {quat. }}\right), 144.21$ ( $\left.\mathrm{C}_{1^{\prime \prime}}, \mathrm{C}_{\text {quat. }}\right), 138.15\left(\mathrm{C}_{4^{\prime \prime}},-\mathrm{CH}\right), 136.36\left(\mathrm{C}_{3}\right.$, $\left.\mathrm{C}_{\text {quat. }}\right), 135.32\left(\mathrm{C}_{5^{\prime \prime}},-\mathrm{CH}\right), 132.87\left(\mathrm{C}_{5^{\prime \prime} \mathrm{a}}, \mathrm{C}_{\text {quat. }}\right), 131.39\left(\mathrm{C}_{3^{\prime \prime}}\right.$,

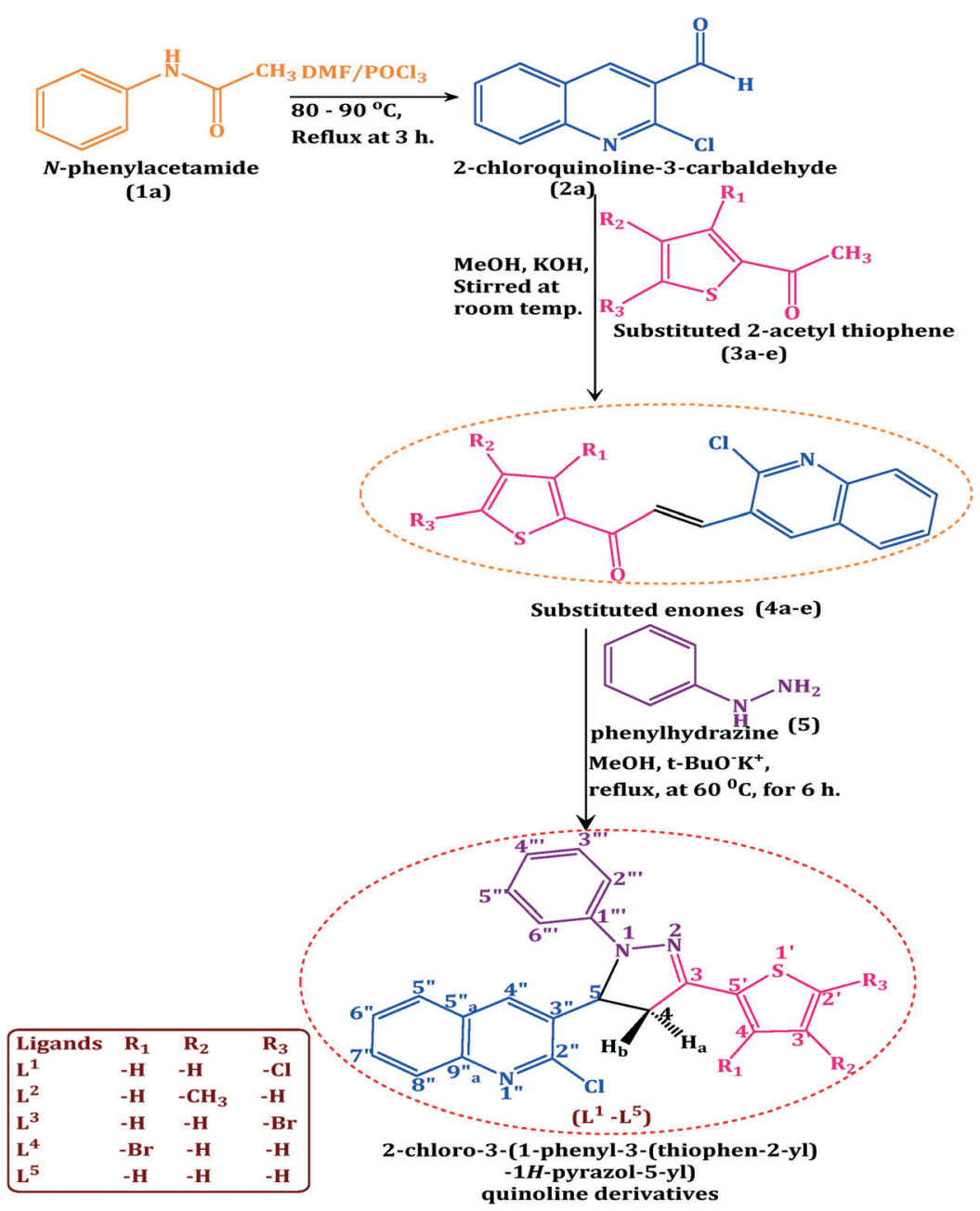

Scheme 1 Synthesis of the 5-quinoline based 1,3,5-tri-substituted pyrazole derivative ligands $\left(\mathrm{L}^{1}-\mathrm{L}^{5}\right)$. 
$\left.\mathrm{C}_{\text {quat. }}\right), 130.55\left(\mathrm{C}_{7^{\prime \prime}},-\mathrm{CH}\right), 129.66\left(\mathrm{C}_{3^{\prime \prime \prime}, 5^{\prime \prime}},-\mathrm{CH}\right), 129.56\left(\mathrm{C}_{8^{\prime \prime}}\right.$, $-\mathrm{CH}), 128.69\left(\mathrm{C}_{4^{\prime}},-\mathrm{CH}\right), 128.04\left(\mathrm{C}_{5^{\prime}}, \mathrm{C}_{\text {quat. }}\right), 127.99\left(\mathrm{C}_{6^{\prime \prime}},-\mathrm{CH}\right)$, $127.44\left(\mathrm{C}_{5},-\mathrm{CH}\right), 123.37\left(\mathrm{C}_{3^{\prime}},-\mathrm{CH}\right), 119.55\left(\mathrm{C}_{4^{\prime \prime \prime}},-\mathrm{CH}\right), 113.26$ $\left(\mathrm{C}_{2^{\prime \prime \prime}, 6^{\prime \prime \prime}},-\mathrm{CH}\right), 113.16\left(\mathrm{C}_{4},-\mathrm{CH}_{2}\right)$ [Total signal observed = 20: signal of $\mathrm{C}$ and $\mathrm{CH}_{2}=9$ (thiophene- $\mathrm{C}=2$, pyrazole- $\mathrm{C}=1$, phenyl ring-C $=1$, quinoline- $\mathrm{C}=4$, pyrazole- $\mathrm{CH}_{2}=1$ ), signal of $\mathrm{CH}$ $=11$ (thiophene- $\mathrm{CH}=2$, pyrazole- $\mathrm{CH}=1$, phenyl ring- $\mathrm{CH}=3$, quinoline-CH $=5]$. FT-IR $(\mathrm{KBr}):\left(\mathrm{cm}^{-1}\right): 3039 v_{(=\mathrm{C}-\mathrm{H}) \operatorname{ar}}(\mathrm{w})$, 1596-1558 $v_{(\mathrm{C}=\mathrm{N})}(\mathrm{s}), 1496-1458 v_{(\mathrm{C}=\mathrm{C}) \text { conjugated alkenes }}(\mathrm{m})$, $1388 v_{(\mathrm{C}-\mathrm{H}) \text { bonding }}(\mathrm{m}), 1319 v_{(\mathrm{C}-\mathrm{N})}, 1234 v_{(\mathrm{C}-\mathrm{C}) \text { alkanes }}(\mathrm{s}), 1041$ $v_{(\mathrm{C}-\mathrm{S}-\mathrm{C}) \text { stre. (thiophene ring) }},(\mathrm{w}), 786-678 v_{(\mathrm{Ar}-\mathrm{H}) 2}$ adjacent hydrogen $(\mathrm{s})$.

\section{Preparation of 2-chloro-3-(3-(4-methylthiophen-2-yl)-1-phenyl-} $1 H$-pyrazol-5-yl) quinoline $\left(\mathrm{L}^{2}\right)$

The above-named product was synthesized using phenyl hydrazine (5a) (0.389 g, $7 \mathrm{mmol})$ and different substituted quinoline derivative enones (4a-4e) $(1 \mathrm{~g}, 7 \mathrm{mmol})$ after reflux for $5 \mathrm{~h}$ in methanolic solution as described in general process. Colour: yellowish orange crystal, yield: $90 \%$, mol. wt: $403.93 \mathrm{~g} \mathrm{~mol}{ }^{-1}$, m.p.: $275{ }^{\circ} \mathrm{C}$; anal. calc. (\%) for $\mathrm{C}_{23} \mathrm{H}_{18} \mathrm{ClN}_{3} \mathrm{~S}$ : C, 68.73; H, 4.01; N, 10.46; S, 7.98. Found (\%): C, 68.56; H, 4.05; N, 10.26; S, 7.89. UV-vis: $\lambda(\mathrm{nm})(\varepsilon$, $\mathrm{M}^{-1} \mathrm{~cm}^{-1}$ ): 255 (36 560), 313 (6590). Mass $\mathrm{m} / \mathrm{z}$ (\%): 402.08 $[\mathrm{M}]^{+} .{ }^{1} \mathrm{H}$ NMR (400 MHz, DMSO-d 6 ) $\delta / \mathrm{ppm}: 3.286$ (1H, dd, $\left.{ }^{3} J_{1}=8.8 \mathrm{~Hz},{ }^{3} J_{2}=6.0 \mathrm{~Hz}, \mathrm{H}-\mathrm{a}\right), 4.121\left(1 \mathrm{H}, \mathrm{dd},{ }^{3} J_{1}=8.4 \mathrm{~Hz}\right.$, $\left.{ }^{3} J_{2}=6.4 \mathrm{~Hz}, \mathrm{H}-\mathrm{b}\right), 5.739\left(1 \mathrm{H}, \mathrm{dd},{ }^{3} J_{1}=8.0 \mathrm{~Hz},{ }^{3} J_{2}=6.4 \mathrm{~Hz}\right.$,

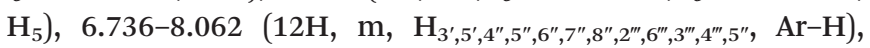
$2.177\left(3 \mathrm{H}, \mathrm{s},-\mathrm{CH}_{3}\right) .{ }^{13} \mathrm{C}$ NMR (100 MHz, DMSO-d 6 ) $\delta / \mathrm{ppm}$ : $148.91\left(\mathrm{C}_{2^{\prime \prime}}, \mathrm{C}_{\text {quat. }}\right) 146.95$ (9"a, $\left.\mathrm{C}_{\text {quat. }}\right), 144.75\left(\mathrm{C}_{2^{\prime}}, \mathrm{C}_{\text {quat. }}\right)$, $144.27\left(\mathrm{C}_{1^{\prime \prime}}, \mathrm{C}_{\text {quat. }}\right), 138.17\left(\mathrm{C}_{4^{\prime}}, \mathrm{C}_{\text {quat. }}\right), 136.86\left(\mathrm{C}_{3}, \mathrm{C}_{\text {quat. }}\right)$, $135.38\left(\mathrm{C}_{5^{\prime \prime}},-\mathrm{CH}\right), 132.87\left(\mathrm{C}_{5^{\prime \prime}},-\mathrm{CH}\right), 131.39\left(\mathrm{C}_{3^{\prime \prime}}, \mathrm{C}_{\text {quat. }}\right)$, $130.55\left(\mathrm{C}_{7 "},-\mathrm{CH}\right), 129.68\left(\mathrm{C}_{3^{\prime \prime \prime}, 5 " 5^{\prime \prime}},-\mathrm{CH}\right), 129.56\left(\mathrm{C}_{8^{\prime \prime}}-\mathrm{CH}\right)$, $128.89\left(\mathrm{C}_{4^{\prime \prime}},-\mathrm{CH}\right), 128.04\left(\mathrm{C}_{6^{\prime \prime}},-\mathrm{CH}\right), 127.99\left(\mathrm{C}_{5},-\mathrm{CH}\right)$, $127.44\left(\mathrm{C}_{3^{\prime}},-\mathrm{CH}\right), 123.87\left(\mathrm{C}_{5^{\prime}},-\mathrm{CH}\right), 119.55\left(\mathrm{C}_{4^{\prime \prime}},-\mathrm{CH}\right)$, $113.86\left(\mathrm{C}_{2^{\prime \prime \prime}, 6^{\prime \prime \prime}},-\mathrm{CH}\right), 113.18\left(\mathrm{C}_{4},-\mathrm{CH}_{2}\right), 15.48\left(-\mathrm{CH}_{3}\right)$. [Total signal observed $=21$ : signal of $\mathrm{C}$ and $\mathrm{CH}_{2}=9$ (thiophene- $\mathrm{C}$ $=2$, pyrazole- $\mathrm{C}=1$, phenyl ring- $\mathrm{C}=1$, quinoline- $\mathrm{C}=4$, pyrazole- $\mathrm{CH}_{2}=1$ ), signal of $\mathrm{CH}$ and $\mathrm{CH}_{3}=12$ (thiophene$\mathrm{CH}=2$, pyrazole- $\mathrm{CH}=1$, phenyl ring- $\mathrm{CH}=3$, quinoline- $\mathrm{CH}$

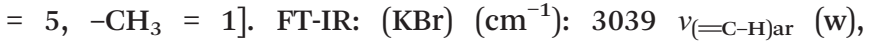

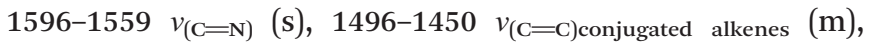
$1388 v_{(\mathrm{C}-\mathrm{H}) \text { bonding }}(\mathrm{m}), 1319 v_{(\mathrm{C}-\mathrm{N})}, 1234 v_{(\mathrm{C}-\mathrm{C}) \text { alkanes }}(\mathrm{s}), 1041$ $v_{(\mathrm{C}-\mathrm{S}-\mathrm{C}) \text { stre. (thiophene ring) }}(\mathrm{w}), 779-678 v_{(\mathrm{Ar}-\mathrm{H}) 2}$ adjacent hydrogen $(\mathrm{s})$.

\section{Preparation of 3-(3-(5-bromothiophen-2-yl)-1-phenyl-1H- pyrazol-5-yl)-2-chloroquinoline $\left(\mathrm{L}^{3}\right)$}

The above-named product was synthesized using phenyl hydrazine (5a) (0.389 g, $7 \mathrm{mmol}$ ) and different substituted quinoline derivative enones $(\mathbf{4 a}-\mathbf{4 e})(1 \mathrm{~g}, 7 \mathrm{mmol})$ after reflux for $5 \mathrm{~h}$ in methanolic solution as described in general process. Colour: yellowish orange crystal, yield: $93 \%$, mol. wt: $468.80 \mathrm{~g}$ $\mathrm{mol}^{-1}$, m.p.: $268{ }^{\circ} \mathrm{C}$; anal. calc. (\%) For $\mathrm{C}_{22} \mathrm{H}_{15} \mathrm{BrClN}_{3} \mathrm{~S}$ : C, 56.61; H, 2.81; N, 9.00; S, 6.87. Found (\%): C, 56.76; H, 2.79; $\mathrm{N}, 9.26$; S, 7.02. UV-vis: $\lambda(\mathrm{nm})\left(\varepsilon, \mathrm{M}^{-1} \mathrm{~cm}^{-1}\right): 258$ (37.620), 321 (9730). Mass $m / z$ (\%): $467.08[\mathrm{M}]^{+} .{ }^{1} \mathrm{H}$ NMR (400 MHz,
DMSO-d $\left.{ }_{6}\right) \delta /$ ppm: $3.288\left(1 \mathrm{H}, \mathrm{dd},{ }^{3} J_{1}=11.2 \mathrm{~Hz},{ }^{3} J_{2}=6.8 \mathrm{~Hz}, \mathrm{H}-\right.$ a), $4.121\left(1 \mathrm{H}, \mathrm{dd},{ }^{3} J_{1}=8.8 \mathrm{~Hz},{ }^{3} J_{2}=4.4 \mathrm{~Hz}, \mathrm{H}-\mathrm{b}\right), 5.728(1 \mathrm{H}$, $\left.\mathrm{dd},{ }^{3} J_{1}=9.6 \mathrm{~Hz},{ }^{3} J_{2}=9.2 \mathrm{~Hz}, \mathrm{H}_{5}\right), 6.739-8.087(12 \mathrm{H}, \mathrm{m}$, $\mathrm{H}_{3^{\prime}, 4^{\prime}, 4^{\prime \prime}, 5^{\prime \prime}, 6^{\prime \prime}, 7^{\prime \prime}, 8^{\prime \prime}, 2^{\prime \prime \prime}, 6^{\prime \prime}, 3^{\prime \prime \prime}, 5^{\prime \prime \prime}, 4^{\prime \prime \prime},}$ Ar-H). ${ }^{13} \mathrm{C}$ NMR (100 MHz, DMSO$\left.\mathrm{d}_{6}\right) \delta /$ ppm: $148.99\left(\mathrm{C}_{2^{\prime \prime}}, \mathrm{C}_{\text {quat. }}\right), 146.90\left(\mathrm{C}_{9^{\prime \prime}}, \mathrm{C}_{\text {quat. }}\right), 144.88$ $\left(\mathrm{C}_{2^{\prime}}, \mathrm{C}_{\text {quat. }}\right), 144.28\left(\mathrm{C}_{1^{\prime \prime}}, \mathrm{C}_{\text {quat. }}\right), 138.67\left(\mathrm{C}_{4^{\prime \prime}},-\mathrm{CH}\right), 136.82\left(\mathrm{C}_{3}\right.$, $\left.\mathrm{C}_{\text {quat. }}\right), 135.48\left(\mathrm{C}_{5^{\prime \prime}},-\mathrm{CH}\right), 132.87\left(\mathrm{C}_{5^{\prime \prime}}, \mathrm{C}_{\text {quat. }}\right), 131.59\left(\mathrm{C}_{3^{\prime \prime}}\right.$, $\left.\mathrm{C}_{\text {quat. }}\right), 130.55\left(\mathrm{C}_{7^{\prime \prime}},-\mathrm{CH}\right), 129.98\left(\mathrm{C}_{3^{\prime \prime \prime}, 5^{\prime \prime \prime}},-\mathrm{CH}\right), 129.56\left(\mathrm{C}_{8^{\prime \prime}}\right.$, $-\mathrm{CH}), 128.89\left(\mathrm{C}_{4^{\prime}},-\mathrm{CH}\right), 128.04\left(\mathrm{C}_{6^{\prime \prime}},-\mathrm{CH}\right), 127.99\left(\mathrm{C}_{5},-\mathrm{CH}\right)$, $127.44\left(\mathrm{C}_{3^{\prime}},-\mathrm{CH}\right), 123.87\left(\mathrm{C}_{2^{\prime \prime \prime}, 6^{\prime \prime \prime}}\right), 119.95\left(\mathrm{C}_{4^{\prime \prime \prime}},-\mathrm{CH}\right), 113.89$ $\left(\mathrm{C}_{5}, \mathrm{C}_{\text {quat. }}\right), 113.28\left(\mathrm{C}_{4},-\mathrm{CH}_{2}\right)$. [Total signal observed $=20$ : signal of $\mathrm{C}$ and $\mathrm{CH}_{2}=9$ (thiophene- $\mathrm{C}=2$, pyrazole- $\mathrm{C}=1$, phenyl ring-C $=1$, quinoline- $\mathrm{C}=4$, pyrazole- $\mathrm{CH}_{2}=1$ ), signal of $\mathrm{CH}$ $=11$ (thiophene- $\mathrm{CH}=2$, pyrazole- $\mathrm{CH}=1$, phenyl ring- $\mathrm{CH}=3$,

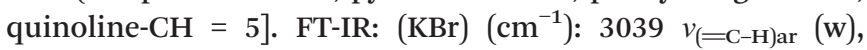
1596-1559 $v_{(\mathrm{C}=\mathrm{N})}(\mathrm{s}), 1496-1450 \quad v_{(\mathrm{C}=\mathrm{C}) \text { conjugated alkenes }}(\mathrm{m})$, $1388 v_{(\mathrm{C}-\mathrm{H}) \text { bonding }}(\mathrm{m}), 1320 v_{(\mathrm{C}-\mathrm{N})}, 1234 v_{(\mathrm{C}-\mathrm{C}) \text { alkanes }}(\mathrm{s}), 1041$ $v_{(\mathrm{C}-\mathrm{S}-\mathrm{C}) \text { stre. (thiophene ring) }},(\mathrm{w}), 779-678 v_{(\mathrm{Ar}-\mathrm{H}) 2}$ adjacent hydrogen $(\mathrm{s})$.

\section{Preparation of 3-(3-(3-bromothiophen-2-yl)-1-phenyl-1H- pyrazol-5-yl)-2-chloroquinoline $\left(\mathrm{L}^{4}\right)$}

The above-named product was synthesized using phenyl hydrazine (5a) (0.389 g, $7 \mathrm{mmol}$ ) and different substituted quinoline derivative enones $(\mathbf{4 a}-\mathbf{4 e})(1 \mathrm{~g}, 7 \mathrm{mmol})$ after reflux for $5 \mathrm{~h}$ in DMF solution as described in general process. Colour: yellowish orange crystal, yield: $95 \%$, mol. wt: $468.80 \mathrm{~g} \mathrm{~mol}^{-1}$, m.p.: $263{ }^{\circ} \mathrm{C}$; anal. calc. (\%) for $\mathrm{C}_{22} \mathrm{H}_{15} \mathrm{BrClN}_{3} \mathrm{~S}$ : C, 56.61; $\mathrm{H}$, 2.81; N, 9.00; S, 6.87. Found (\%): C, 56.96; H, 2.44; N, 9.06; S, 6.92. UV-vis: $\lambda$ (nm) $\left(\varepsilon, \mathrm{M}^{-1} \mathrm{~cm}^{-1}\right): 260$ (32 210), 307 (9520). Mass $m / z$ (\%): $467.57[\mathrm{M}]^{+} .{ }^{1} \mathrm{H}$ NMR (400 MHz, DMSO-d $\left.{ }_{6}\right) \delta /$ ppm: $3.272\left(1 \mathrm{H}, \mathrm{dd},{ }^{3} J_{1}=6.4 \mathrm{~Hz},{ }^{3} J_{2}=10.4 \mathrm{~Hz}, \mathrm{H}-\mathrm{a}\right), 4.116$ $\left(1 \mathrm{H}, \mathrm{dd},{ }^{3} J_{1}=11.6 \mathrm{~Hz},{ }^{3} J_{2}=12.8 \mathrm{~Hz}, \mathrm{H}-\mathrm{b}\right), 5.789\left(1 \mathrm{H}, \mathrm{dd},{ }^{3} J_{1}=\right.$ $\left.6.4 \mathrm{~Hz},{ }^{3} J_{2}=9.6 \mathrm{~Hz}, \mathrm{H}_{5}\right), \quad 6.763-8.084 \quad(12 \mathrm{H}, \quad \mathrm{m}$, $\left.\mathrm{H}_{\left.4^{\prime}, 5^{\prime}, 4^{\prime \prime}, 5^{\prime \prime}, 6^{\prime \prime}, 7^{\prime \prime}, 8^{\prime \prime}, 2^{\prime \prime \prime}, 6^{\prime \prime \prime}, 3^{\prime \prime \prime}, 4^{\prime \prime \prime}, 5^{\prime \prime \prime}\right)}\right){ }^{13} \mathrm{C}$ NMR (100 MHz, DMSO-d 6 ) $\delta /$ ppm: 148.98 ( $\left.\mathrm{C}_{2^{\prime \prime}}, \mathrm{C}_{\text {quat. }}\right), 146.80$ ( $\left.\mathrm{C}_{9^{\prime \prime}}, \mathrm{C}_{\text {quat. }}\right), 144.82\left(\mathrm{C}_{2^{\prime}}\right.$, $\left.\mathrm{C}_{\text {quat. }}\right), 144.48\left(\mathrm{C}_{1^{\prime \prime}}, \mathrm{C}_{\text {quat. }}\right), 138.64\left(\mathrm{C}_{4^{\prime \prime}},-\mathrm{CH}\right), 136.83\left(\mathrm{C}_{3}\right.$, $\left.\mathrm{C}_{\text {quat. }}\right), 135.48\left(\mathrm{C}_{5^{\prime \prime}},-\mathrm{CH}\right), 132.87\left(\mathrm{C}_{5^{\prime \prime}}, \mathrm{C}_{\text {quat. }}\right), 131.59\left(\mathrm{C}_{3^{\prime \prime}}\right.$, $\left.\mathrm{C}_{\text {quat. }}\right), 130.53\left(\mathrm{C}_{7^{\prime \prime}},-\mathrm{CH}\right), 129.93\left(\mathrm{C}_{3^{\prime \prime \prime}, 5^{\prime \prime}},-\mathrm{CH}\right), 129.56\left(\mathrm{C}_{8^{\prime \prime}}\right.$, $-\mathrm{CH}), 128.89\left(\mathrm{C}_{4^{\prime}},-\mathrm{CH}\right), 128.34\left(\mathrm{C}_{5^{\prime}},-\mathrm{CH}\right), 127.99\left(\mathrm{C}_{6^{\prime \prime}},-\mathrm{CH}\right)$, $127.44\left(\mathrm{C}_{5},-\mathrm{CH}\right), 123.87\left(\mathrm{C}_{4^{\prime \prime \prime}},-\mathrm{CH}\right), 119.25\left(\mathrm{C}_{2^{\prime \prime \prime}, 6^{\prime \prime \prime},}, \mathrm{CH}\right)$, $113.89\left(\mathrm{C}_{4},-\mathrm{CH}_{2}\right), 112.92\left(\mathrm{C}_{3^{\prime}}, \mathrm{C}_{\text {quat. }}\right)$. [Total signal observed $=$ 20: signal of $\mathrm{C}$ and $\mathrm{CH}_{2}=9$ (thiophene- $\mathrm{C}=2$, pyrazole- $\mathrm{C}=1$, phenyl ring- $\mathrm{C}=1$, quinoline- $\mathrm{C}=4$, pyrazole- $\mathrm{CH}_{2}=1$ ), signal of $\mathrm{CH}=11$ (thiophene- $\mathrm{CH}=2$, pyrazole- $\mathrm{CH}=1$, phenyl ring- $\mathrm{CH}=$ 3 , quinoline-CH = 5]. FT-IR: $(\mathrm{KBr})\left(\mathrm{cm}^{-1}\right): 3039 v_{(=\mathrm{C}-\mathrm{H}) \mathrm{ar}}(\mathrm{w})$, 1596-1542 $v_{(\mathrm{C}=\mathrm{N})}(\mathrm{s}), 1496-1458 v_{(\mathrm{C}=\mathrm{C}) \text { conjugated alkenes }}(\mathrm{m})$, $1388 v_{(\mathrm{C}-\mathrm{H}) \text { bonding }}(\mathrm{m}), 1311 v_{(\mathrm{C}-\mathrm{N})}, 1234 v_{(\mathrm{C}-\mathrm{C}) \text { alkanes }}(\mathrm{s}), 1042$ $v_{(\mathrm{C}-\mathrm{S}-\mathrm{C}) \text { stre. (thiophene ring) }},(\mathrm{W}), 786-678 v_{(\mathrm{Ar}-\mathrm{H}) 2}$ adjacent hydrogen $(\mathrm{s})$.

\section{Preparation of 2-chloro-3-(1-phenyl-3-(thiophen-2-yl)-1H- pyrazol-5-yl)quinoline $\left(\mathrm{L}^{5}\right)$}

The above-named product was synthesized using phenyl hydrazine (5a) (0.784 g, $7 \mathrm{mmol}$ ) and different substituted quinoline derivative enones (4a-4e) $(0.953 \mathrm{~g}, 7 \mathrm{mmol})$ after reflux for $5 \mathrm{~h}$ in methanolic solution as described in general 
process. Colour: yellowish orange crystal, yield: $92 \%$, mol. wt: $389.90 \mathrm{~g} \mathrm{~mol}^{-1}$, m.p.: $260{ }^{\circ} \mathrm{C}$; anal. calc. (\%) for $\mathrm{C}_{22} \mathrm{H}_{16} \mathrm{ClN}_{3} \mathrm{~S}$ : C, 68.12; H, 3.64; N, 10.83; S, 8.27. Found (\%): C, 68.06; H, 3.44; N, 10.56; S, 8.32. UV-vis: $\lambda(\mathrm{nm})\left(\varepsilon, \mathrm{M}^{-1} \mathrm{~cm}^{-1}\right): 264$ (31,580), 307 (14,030). LC-MS $m / z$ (\%): $388.89[\mathrm{M}]^{+} .{ }^{1} \mathrm{H}$ NMR (400 MHz, DMSO-d $)_{6} \delta /$ ppm: $3.272\left(1 \mathrm{H}, \mathrm{dd},{ }^{3} J_{1}=9.6 \mathrm{~Hz},{ }^{3} J_{2}=\right.$ $10.8 \mathrm{~Hz}, \mathrm{H}-\mathrm{a}), 4.122\left(1 \mathrm{H}, \mathrm{dd},{ }^{3} J_{1}=11.6 \mathrm{~Hz},{ }^{3} J_{2}=13.6 \mathrm{~Hz}, \mathrm{H}-\right.$ b), $5.791\left(1 \mathrm{H}, \mathrm{dd},{ }^{3} J_{1}=10.4 \mathrm{~Hz},{ }^{3} J_{2}=8.8 \mathrm{~Hz}, \mathrm{H}_{5}\right), 6.761-8.081$ $\left(13 \mathrm{H}, \mathrm{m}, \mathrm{H}_{\left.3^{\prime}, 4^{\prime}, 5^{\prime}, 4^{\prime \prime}, 5^{\prime \prime}, 6^{\prime \prime}, 7^{\prime \prime}, 8^{\prime \prime}, 2^{\prime \prime \prime}, 3^{\prime \prime \prime}, 4^{\prime \prime \prime}, 5^{\prime \prime \prime}, 6^{\prime \prime \prime}\right) .}{ }^{13} \mathrm{C}\right.$ NMR (100 MHz, DMSO-d $\left.{ }_{6}\right) \delta /$ ppm: $148.34\left(\mathrm{C}_{2^{\prime \prime}}, \mathrm{C}_{\text {quat. }}\right), 146.20$ ( $\left.\mathrm{C}_{9^{\prime \prime}}, \mathrm{C}_{\text {quat. }}\right)$, $144.83\left(\mathrm{C}_{2^{\prime}}, \mathrm{C}_{\text {quat. }}\right), 144.43\left(\mathrm{C}_{1^{\prime \prime}}, \mathrm{C}_{\text {quat. }}\right), 138.64\left(\mathrm{C}_{4^{\prime \prime}},-\mathrm{CH}\right)$, $136.84\left(\mathrm{C}_{3}, \mathrm{C}_{\text {quat. }}\right), 135.48\left(\mathrm{C}_{5^{\prime \prime}},-\mathrm{CH}\right), 132.80$ ( $\left.\mathrm{C}_{5^{\prime \prime}}, \mathrm{C}_{\text {quat. }}\right)$, $131.59\left(\mathrm{C}_{3^{\prime \prime}}, \mathrm{C}_{\text {quat. }}\right), 130.50\left(\mathrm{C}_{7^{\prime \prime}},-\mathrm{CH}\right), 129.93\left(\mathrm{C}_{3^{\prime \prime \prime}, 5^{\prime \prime \prime}},-\mathrm{CH}\right)$, $129.06\left(\mathrm{C}_{8^{\prime \prime}},-\mathrm{CH}\right), 128.89\left(\mathrm{C}_{4^{\prime}},-\mathrm{CH}\right), 128.34\left(\mathrm{C}_{5^{\prime}},-\mathrm{CH}\right), 127.90$ $\left(\mathrm{C}_{6^{\prime \prime}},-\mathrm{CH}\right), 127.04\left(\mathrm{C}_{5},-\mathrm{CH}\right), 123.87\left(\mathrm{C}_{3^{\prime}},-\mathrm{CH}\right), 119.25\left(\mathrm{C}_{4^{\prime \prime \prime}}\right.$, $-\mathrm{CH}), 113.09\left(\mathrm{C}_{2^{\prime \prime \prime}, 6^{\prime \prime}},-\mathrm{CH}\right), 112.92\left(\mathrm{C}_{4},-\mathrm{CH}_{2}\right)$. [Total signal observed $=20$ : signal of $\mathrm{C}$ and $\mathrm{CH}_{2}=8$ (thiophene- $\mathrm{C}=1$, pyrazole- $\mathrm{C}=1$, phenyl ring- $\mathrm{C}=1$, quinoline- $\mathrm{C}=4$, pyrazole$\mathrm{CH}_{2}=1$ ), signal of $\mathrm{CH}=12$ (thiophene- $\mathrm{CH}=3$, pyrazole- $\mathrm{CH}=$ 1, phenyl ring-CH $=3$, quinoline-CH = 5]. FT-IR: $(\mathrm{KBr})\left(\mathrm{cm}^{-1}\right)$ : $3038 v_{(=\mathrm{C}-\mathrm{H}) \operatorname{ar}}(\mathrm{w}), 1596-1543 v_{(\mathrm{C}=\mathrm{N})}(\mathrm{s}), 1496-1450 v_{(\mathrm{C}=\mathrm{C}) \text { conju- }}$ gated alkenes $(\mathrm{m}), 1387 v_{(\mathrm{C}-\mathrm{H}) \text { bonding }}(\mathrm{m}), 1311 v_{(\mathrm{C}-\mathrm{N})}, 1234$ $v_{(\mathrm{C}-\mathrm{C}) \text { alkanes }}(\mathrm{s}), 1042 v_{(\mathrm{C}-\mathrm{S}-\mathrm{C}) \text { stre. (thiophene ring), }(\mathrm{w}), 786-678}$ $v_{(\mathrm{Ar}-\mathrm{H}) 2}$ adjacent hydrogen $(\mathrm{s})$.

\section{General synthesis of platinum(II) complexes (I-V)}

The complexes were synthesized using the method proposed by Hodges and Rund. ${ }^{17}$ Complexes (I-V) were synthesized by refluxing a $1: 1$ ratio of $\left(\mathbf{L}^{1}-\mathbf{L}^{5}\right)(0.25 \mathrm{mmol})$ and $\mathrm{K}_{2} \mathrm{PtCl}_{4}(0.25$ $\mathrm{mmol})$ in water-methanol system $(50 \mathrm{~mL})$ at $60{ }^{\circ} \mathrm{C}$ with $1-2$ drops of hydrochloric acid (free acid is used to avoid displacement of $\mathrm{Cl}^{-}$by $-\mathrm{OH}$ ) until the solution became colourless $(0.5-6 \mathrm{~h})$. The reaction mixture was allowed to cool at room temperature. The obtained product was washed with hot water and dried under vacuum. This procedure was reported in the literature. ${ }^{18}$ The proposed reaction of platinum(II) complexes is represented in Scheme 2.

\section{Preparation of complex $\left[\operatorname{Pt}\left(\mathbf{L}^{1}\right) \mathrm{Cl}_{2}\right]$ (I)}

The above-named product was synthesized using potassium tetrachloroplatinate salt $\left(\mathrm{K}_{2} \mathrm{PtCl}_{4}\right)(0.103 \mathrm{~g}, 0.25 \mathrm{mmol})$ and ligands $\left(\mathbf{L}^{1}\right)(0.097 \mathrm{~g}, 0.25 \mathrm{mmol})$ in $1: 1$ ratio, after reflux for 6 $\mathrm{h}$ in $\mathrm{MeOH} / \mathrm{H}_{2} \mathrm{O}$ system as described in general process. Colour: brown powder, yield: $91 \%$, mol. wt: $690.33 \mathrm{~g} \mathrm{~mol}^{-1}$, m.p.: $>300{ }^{\circ} \mathrm{C}$; anal. calc. (\%) for $\mathrm{C}_{22} \mathrm{H}_{15} \mathrm{Cl}_{4} \mathrm{~N}_{3}$ PtS: C, 38.28; H, 2.19; N, 6.09; Pt, 28.26; S, 4.64. Found (\%): C, 38.76; H, 2.38; N, 5.87; Pt, 28.98; S, 5.29. Conductance: $22 \Omega^{-1} \mathrm{~cm}^{2} \mathrm{~mol}^{-1}$. UVvis: $\lambda(\mathrm{nm})\left(\varepsilon, \mathrm{M}^{-1} \mathrm{~cm}^{-1}\right)$ : 259 (36960), 304 (18.860), 374 (8260). ${ }^{1} \mathrm{H}$ NMR (400 MHz, DMSO-d 6 ) $\delta /$ ppm: 3.288 (1H, dd, $\left.{ }^{3} J_{1}=10.8 \mathrm{~Hz},{ }^{3} J_{2}=10.8 \mathrm{~Hz}, \mathrm{H}-\mathrm{a}\right), 4.122\left(1 \mathrm{H}, \mathrm{dd},{ }^{3} J_{1}=10.00\right.$ $\left.\mathrm{Hz},{ }^{3} J_{2}=6.0 \mathrm{~Hz}, \mathrm{H}-\mathrm{b}\right), 5.729\left(1 \mathrm{H}, \mathrm{dd},{ }^{3} J_{1}=10.4 \mathrm{~Hz},{ }^{3} J_{2}=8.0\right.$ $\mathrm{Hz}, \mathrm{H}_{5}$ ), 7.201-8.799 (12H, m, $\mathrm{H}_{\left.3^{\prime}, 4,4^{\prime \prime}, 5^{\prime \prime}, 6^{\prime \prime}, 7^{\prime \prime}, 8^{\prime \prime}, 2^{\prime \prime \prime}, 3^{\prime \prime \prime}, 4^{\prime \prime \prime}, 5^{\prime \prime \prime}, 6^{\prime \prime \prime}\right) .}{ }^{13} \mathrm{C}$ NMR (100 MHz, DMSO-d $\left.{ }_{6}\right) \delta /$ ppm: $155.17\left(\mathrm{C}_{2^{\prime \prime}}, \mathrm{C}_{\text {quat. }}\right), 153.76$ ( $\left.\mathrm{C}_{5^{\prime}}, \mathrm{C}_{\text {quat. }}\right), 151.61$ ( $\left.\mathrm{C}_{9^{\prime \prime}}, \mathrm{C}_{\text {quat. }}\right), 150.70\left(\mathrm{C}_{5},-\mathrm{CH}\right), 149.95\left(\mathrm{C}_{4^{\prime \prime}}\right.$, $-\mathrm{CH}), 145.23\left(\mathrm{C}_{3^{\prime}},-\mathrm{CH}\right), 138.13\left(\mathrm{C}_{4^{\prime}},-\mathrm{CH}\right), 135.83\left(\mathrm{C}_{5^{\prime \prime}},-\mathrm{CH}\right)$, $132.57\left(\mathrm{C}_{5^{\prime \prime}}, \mathrm{C}_{\text {quat. }}\right), 132.48\left(\mathrm{C}_{3^{\prime \prime}}, \mathrm{C}_{\text {quat. }}\right), 128.61\left(\mathrm{C}_{8^{\prime \prime}},-\mathrm{CH}\right)$,

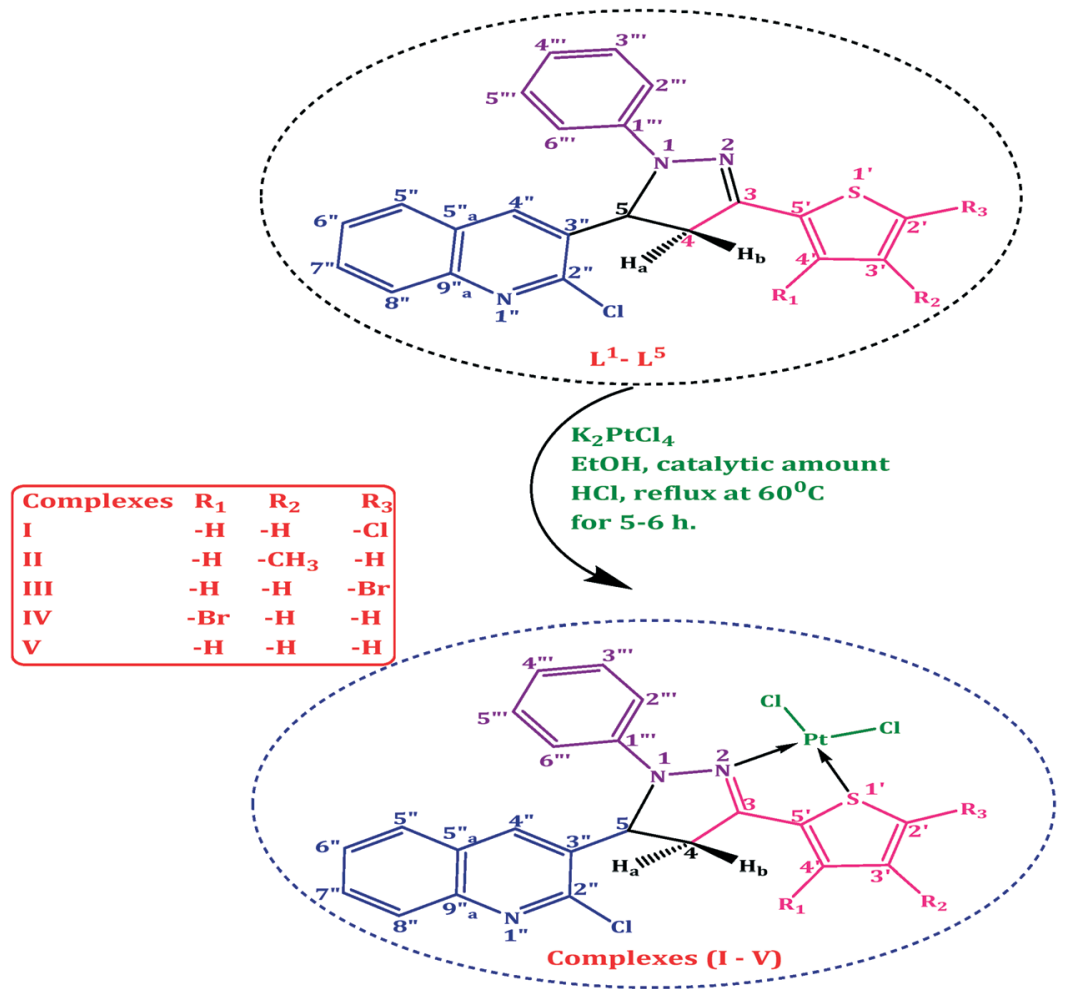

Scheme 2 Synthesis of the bidentate N/S-donor ligands coordinate to designed platinum(II) complexes (I-V). 
$127.84\left(\mathrm{C}_{2^{\prime \prime \prime}, 6^{\prime \prime \prime}},-\mathrm{CH}\right), 127.70\left(\mathrm{C}_{3^{\prime \prime \prime}, 5^{\prime \prime \prime}},-\mathrm{CH}\right), 127.32\left(\mathrm{C}_{4^{\prime \prime \prime}},-\mathrm{CH}\right)$, $125.92\left(\mathrm{C}_{1^{\prime \prime \prime}}, \mathrm{C}_{\text {quat. }}\right), 121.56\left(\mathrm{C}_{7^{\prime \prime}},-\mathrm{CH}\right), 116.31\left(\mathrm{C}_{6^{\prime \prime}},-\mathrm{CH}\right)$, $116.09\left(\mathrm{C}_{4},-\mathrm{CH}_{2}\right), 114.49\left(\mathrm{C}_{2^{\prime}}, \mathrm{C}_{\text {quat. }}\right), 105.00\left(\mathrm{C}_{3}, \mathrm{C}_{\text {quat. }}\right)$. [Total signal observed $=20$ : signal of $\mathrm{C}$ and $\mathrm{CH}_{2}=9$ (thiophene$\mathrm{C}=2$, pyrazole- $\mathrm{C}=1$, phenyl ring- $\mathrm{C}=1$, quinoline- $\mathrm{C}=4$, pyrazole- $\mathrm{CH}_{2}=1$ ), signal of $\mathrm{CH}=11$ (thiophene- $\mathrm{CH}=2$, pyrazole- $\mathrm{CH}=1$, phenyl ring- $\mathrm{CH}=3$, quinoline- $\mathrm{CH}=5]$. FTIR: $(\mathrm{KBr})\left(\mathrm{cm}^{-1}\right): 3170 \quad v_{(=\mathrm{C}-\mathrm{H}) \operatorname{ar}}(\mathrm{w}), 1596-1566 \quad v_{(\mathrm{C}=\mathrm{N})}(\mathrm{s})$, 1504-1458 $v_{(\mathrm{C}=\mathrm{C}) \text { conjugated alkenes }}(\mathrm{m}), 1388-1326 v_{(\mathrm{C}-\mathrm{H}) \text { bonding }}$ $(\mathrm{m}), 1203 v_{(\mathrm{C}-\mathrm{N})}, 1265 v_{(\mathrm{C}-\mathrm{C}) \text { alkanes }}(\mathrm{s}), 1072 v_{(\mathrm{C}-\mathrm{S}-\mathrm{C})}$ stre. (thiophene ring) $(\mathrm{w}), 779-655 v_{(\mathrm{Ar}-\mathrm{H}) 2}$ adjacent hydrogen $(\mathrm{s}), 524 v_{(\mathrm{N}-\mathrm{Pt})}(\mathrm{s}), 509$ $v_{(\mathrm{S}-\mathrm{Pt})}(\mathrm{s})$. LC-MS $(\mathrm{m} / \mathrm{z}): 690.33[\mathrm{M}], 692.30[\mathrm{M}+2], 694.31[\mathrm{M}+$ 4], $696.29[\mathrm{M}+6]$ and $698.32[\mathrm{M}+8]$.

\section{Preparation of complex $\left[\mathrm{Pt}\left(\mathrm{L}^{2}\right) \mathrm{Cl}_{2}\right]$ (II)}

The above-named product was synthesized using potassium tetrachloroplatinate salt $\left(\mathrm{K}_{2} \mathrm{PtCl}_{4}\right)(0.103 \mathrm{~g}, 0.25 \mathrm{mmol})$ and ligands $\left(\mathrm{L}^{2}\right)(0.1 \mathrm{~g}, 0.25 \mathrm{mmol})$ in $1: 1$ ratio, after reflux for $6 \mathrm{~h}$ in $\mathrm{MeOH} / \mathrm{H}_{2} \mathrm{O}$ system as described in general process. Colour: brown powder, yield: $90 \%$, mol. wt: $669.91 \mathrm{~g} \mathrm{~mol}^{-1}$, m.p.: $>300{ }^{\circ} \mathrm{C}$; anal. calc. (\%) for $\mathrm{C}_{23} \mathrm{H}_{18} \mathrm{Cl}_{3} \mathrm{~N}_{3}$ PtS: C, 41.24; $\mathrm{H}, 2.71$; $\mathrm{N}, 6.27$; Pt, 29.12; S, 4.79. Found (\%): C, 40.76; H, 2.38; N, 5.97; Pt, 28.98; S, 5.02. Conductance: $20 \Omega^{-1} \mathrm{~cm}^{2} \mathrm{~mol}^{-1}$. UVvis: $\lambda(\mathrm{nm})\left(\varepsilon, \mathrm{M}^{-1} \mathrm{~cm}^{-1}\right): 269$ (35 730), 295 (20 000), 364 (14 910). ${ }^{1} \mathrm{H}$ NMR (400 MHz, DMSO-d 6 ) $\delta /$ ppm: 3.286 (1H, dd, ${ }^{3} J_{1}$ $\left.=10.4 \mathrm{~Hz},{ }^{3} J_{2}=9.6 \mathrm{~Hz}, \mathrm{H}-\mathrm{a}\right), 4.121\left(1 \mathrm{H}, \mathrm{dd},{ }^{3} J_{1}=10.0 \mathrm{~Hz},{ }^{3} J_{2}=\right.$ $4.8 \mathrm{~Hz}, \mathrm{H}-\mathrm{b}), 5.726\left(1 \mathrm{H}, \mathrm{dd},{ }^{3} J_{1}=9.2 \mathrm{~Hz},{ }^{3} J_{2}=7.6 \mathrm{~Hz}, \mathrm{H}_{5}\right)$, 7.203-8.793 (12H, m, H $\left.3^{\prime}, 5^{\prime}, 4^{\prime \prime}, 5^{\prime \prime}, 6^{\prime \prime}, 7^{\prime \prime}, 8^{\prime \prime}, 2^{\prime \prime \prime}, 3^{\prime \prime \prime}, 4^{\prime \prime \prime}, 5^{\prime \prime \prime}, 6^{\prime \prime \prime}\right), 2.152$ (3H, s, $\left.-\mathrm{CH}_{3}\right) \cdot{ }^{13} \mathrm{C}$ NMR (100 MHz, DMSO-d $\left.{ }_{6}\right) \delta / \mathrm{ppm}: 155.07\left(\mathrm{C}_{2 "}\right.$, $\left.\mathrm{C}_{\text {quat. }}\right), 153.56$ ( $\left.\mathrm{C}_{9^{\prime \prime}}, \mathrm{C}_{\text {quat. }}\right), 151.61\left(\mathrm{C}_{5},-\mathrm{CH}\right), 150.75\left(\mathrm{C}_{4 "}\right.$, $-\mathrm{CH}), 149.95\left(\mathrm{C}_{3^{\prime}},-\mathrm{CH}\right), 145.23\left(\mathrm{C}_{4^{\prime}}, \mathrm{C}_{\text {quat. }}\right), 138.13\left(\mathrm{C}_{5^{\prime \prime}},-\mathrm{CH}\right)$, $135.53\left(\mathrm{C}_{5^{\prime \prime}}, \mathrm{C}_{\text {quat. }}\right), 132.87$ ( $\left.\mathrm{C}_{3^{\prime \prime}}, \mathrm{C}_{\text {quat. }}\right), 132.48\left(\mathrm{C}_{8^{\prime \prime}},-\mathrm{CH}\right)$, $128.61\left(\mathrm{C}_{2^{\prime \prime \prime}, 6^{\prime \prime \prime}},-\mathrm{CH}\right), 127.88\left(\mathrm{C}_{3^{\prime \prime}, 5^{\prime \prime \prime}},-\mathrm{CH}\right), 127.60\left(\mathrm{C}_{4^{\prime \prime \prime}},-\mathrm{CH}\right)$, $127.32\left(\mathrm{C}_{1^{\prime \prime}}, \mathrm{C}_{\text {quat. }}\right), 125.92\left(\mathrm{C}_{7^{\prime \prime}},-\mathrm{CH}\right), 121.66\left(\mathrm{C}_{6^{\prime \prime}},-\mathrm{CH}\right)$, $116.31\left(\mathrm{C}_{4},-\mathrm{CH}_{2}\right), 116.06\left(\mathrm{C}_{5^{\prime}},-\mathrm{CH}\right), 114.69\left(\mathrm{C}_{2^{\prime}}, \mathrm{C}_{\text {quat. }}\right)$, $105.60\left(\mathrm{C}_{3}, \mathrm{C}_{\text {quat. }}\right), 24.69\left(-\mathrm{CH}_{3}\right)$. [Total signal observed $=21$ : signal of $\mathrm{C}$ and $\mathrm{CH}_{2}=9$ (thiophene- $\mathrm{C}=2$, pyrazole- $\mathrm{C}=1$, phenyl ring-C $=1$, quinoline- $\mathrm{C}=4$, pyrazole- $\mathrm{CH}_{2}=1$ ), signal of $\mathrm{CH}$ and $\mathrm{CH}_{3}=12$ (thiophene- $\mathrm{CH}=2$, pyrazole- $\mathrm{CH}=1$, phenyl ring- $\mathrm{CH}=3$, quinoline- $\left.\mathrm{CH}=5,-\mathrm{CH}_{3}=1\right]$. FT-IR: $(\mathrm{KBr})\left(\mathrm{cm}^{-1}\right)$ : $3163 v_{(=\mathrm{C}-\mathrm{H}) \text { ar }}(\mathrm{w}), 1596-1566 v_{(\mathrm{C}=\mathrm{N})}(\mathrm{s}), 1496-1473 v_{(\mathrm{C}=\mathrm{C}) \text { conju- }}$ gated alkenes $(\mathrm{m}), 1380-1326 v_{(\mathrm{C}-\mathrm{H}) \text { bonding }}(\mathrm{m}), 1203 v_{(\mathrm{C}-\mathrm{N})}, 1249$ $v_{(\mathrm{C}-\mathrm{C}) \text { alkanes }}(\mathrm{s}), 1072 v_{(\mathrm{C}-\mathrm{S}-\mathrm{C}) \text { stre. (thiophene ring) }}(\mathrm{w}), 740-686$ $v_{(\mathrm{Ar}-\mathrm{H}) 2}$ adjacent hydrogen $(\mathrm{s}), 555 v_{(\mathrm{N}-\mathrm{Pt})}(\mathrm{s}), 509 v_{(\mathrm{S}-\mathrm{Pt})}(\mathrm{s})$.

\section{Preparation of complex $\left[\mathrm{Pt}\left(\mathrm{L}^{3}\right) \mathrm{Cl}_{2}\right]$ (III)}

The above-named product was synthesized using potassium tetrachloroplatinate salt $\left(\mathrm{K}_{2} \mathrm{PtCl}_{4}\right)(0.103 \mathrm{~g}, 0.25 \mathrm{mmol})$ and ligands $\left(\mathrm{L}^{3}\right)(0.117 \mathrm{~g}, 0.25 \mathrm{mmol})$ in $1: 1$ ratio, after reflux for 6 $\mathrm{h}$ in $\mathrm{MeOH} / \mathrm{H}_{2} \mathrm{O}$ system as described in general process. Colour: brown powder, yield: $88 \%$, mol. wt: $734.78 \mathrm{~g} \mathrm{~mol}^{-1}$, m.p.: $>300{ }^{\circ} \mathrm{C}$; anal. calc. (\%) for $\mathrm{C}_{22} \mathrm{H}_{15} \mathrm{BrCl}_{3} \mathrm{~N}_{3} \mathrm{PtS}$ : C, 35.96; $\mathrm{H}$, 2.06; N, 5.72; Pt, 26.55; S, 4.36. Found (\%): C, 35.76; H, 2.09; $\mathrm{N}, 5.97$; Pt, 26.58; S, 4.12. Conductance: $21 \Omega^{-1} \mathrm{~cm}^{2} \mathrm{~mol}^{-1}$. UV-vis: $\lambda(\mathrm{nm})\left(\varepsilon, \mathrm{M}^{-1} \mathrm{~cm}^{-1}\right): 257$ (33 060), 307 (10 810), 380
(8150). ${ }^{1} \mathrm{H}$ NMR (400 MHz, DMSO-d ${ }_{6}$ ) $\delta / \mathrm{ppm}: 3.286$ (1H, dd, $\left.{ }^{3} J_{1}=9.6 \mathrm{~Hz},{ }^{3} J_{2}=9.2 \mathrm{~Hz}, \mathrm{H}-\mathrm{a}\right), 4.126\left(1 \mathrm{H}, \mathrm{dd},{ }^{3} J_{1}=11.2 \mathrm{~Hz}\right.$, $\left.{ }^{3} \mathrm{~J}_{2}=7.2 \mathrm{~Hz}, \mathrm{H}-\mathrm{b}\right), 5.734\left(1 \mathrm{H}, \mathrm{dd},{ }^{3} J_{1}=9.6 \mathrm{~Hz},{ }^{3} J_{2}=8.8 \mathrm{~Hz}\right.$, $\mathrm{H}_{5}$ ), 7.206-8.795 (12H, m, $\left.\mathrm{H}_{3^{\prime}, 4^{\prime}, 4^{\prime \prime}, 5^{\prime \prime}, 6^{\prime \prime}, 7^{\prime \prime}, 8^{\prime \prime}, 2^{\prime \prime \prime}, 3^{\prime \prime \prime}, 4^{\prime \prime \prime}, 5^{\prime \prime \prime}, 6^{\prime \prime \prime}} \mathrm{Ar}-\mathrm{H}\right) .{ }^{13} \mathrm{C}$ NMR (100 MHz, DMSO-d $\left.{ }_{6}\right) \delta /$ ppm: $155.23\left(\mathrm{C}_{2^{\prime \prime}}, \mathrm{C}_{\text {quat. }}\right), 153.79$ $\left(\mathrm{C}_{5^{\prime}}, \mathrm{C}_{\text {quat. }}\right), 151.11$ ( $\left.\mathrm{C}_{9^{\prime \prime}}, \mathrm{C}_{\text {quat. }}\right), 150.71\left(\mathrm{C}_{5},-\mathrm{CH}\right), 149.95\left(\mathrm{C}_{4^{\prime \prime}}\right.$, $-\mathrm{CH}), 145.53\left(\mathrm{C}_{3^{\prime}},-\mathrm{CH}\right), 138.53\left(\mathrm{C}_{4^{\prime}},-\mathrm{CH}\right), 135.83\left(\mathrm{C}_{5^{\prime \prime}},-\mathrm{CH}\right)$, $132.57\left(\mathrm{C}_{5^{\prime \prime}}, \mathrm{C}_{\text {quat. }}\right), 132.48\left(\mathrm{C}_{3^{\prime \prime}}, \mathrm{C}_{\text {quat. }}\right), 128.61\left(\mathrm{C}_{8^{\prime \prime}},-\mathrm{CH}\right)$, $127.84\left(\mathrm{C}_{2^{\prime \prime \prime}, 6^{\prime \prime \prime}},-\mathrm{CH}\right), 127.50\left(\mathrm{C}_{3^{\prime \prime \prime}, 5^{\prime \prime}},-\mathrm{CH}\right), 127.32\left(\mathrm{C}_{4^{\prime \prime \prime}},-\mathrm{CH}\right)$, $125.92\left(\mathrm{C}_{1^{\prime \prime}}, \mathrm{C}_{\text {quat. }}\right), 121.56\left(\mathrm{C}_{7^{\prime \prime}},-\mathrm{CH}\right), 116.51\left(\mathrm{C}_{6^{\prime \prime}},-\mathrm{CH}\right), 116.09$ $\left(\mathrm{C}_{4},-\mathrm{CH}_{2}\right), 114.49\left(\mathrm{C}_{2^{\prime}}, \mathrm{C}_{\text {quat. }}\right), 105.05\left(\mathrm{C}_{3}, \mathrm{C}_{\text {quat. }}\right)$. [Total signal observed $=20$ : signal of $\mathrm{C}$ and $\mathrm{CH}_{2}=9$ (thiophene- $\mathrm{C}=2$, pyrazole- $\mathrm{C}=1$, phenyl ring- $\mathrm{C}=1$, quinoline- $\mathrm{C}=4$, pyrazole$\mathrm{CH}_{2}=1$ ), signal of $\mathrm{CH}=11$ (thiophene- $\mathrm{CH}=2$, pyrazole- $\mathrm{CH}=$ 1, phenyl ring- $\mathrm{CH}=3$, quinoline-CH $=5]$. FT-IR: $(\mathrm{KBr})\left(\mathrm{cm}^{-1}\right)$ : $3170 v_{(=\mathrm{C}-\mathrm{H}) \text { ar }}(\mathrm{w}), 1596-1566 v_{(\mathrm{C}=\mathrm{N})}(\mathrm{s}), 1450-1504 v_{(\mathrm{C}=\mathrm{C}) \text { conju- }}$ gated alkenes $(\mathrm{m}), 1388-1326 v_{(\mathrm{C}-\mathrm{H}) \text { bonding }}(\mathrm{m}), 1203 v_{(\mathrm{C}-\mathrm{N})}, 1257$

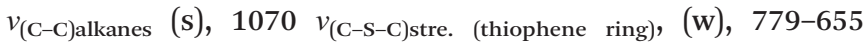
$v_{(\mathrm{Ar}-\mathrm{H}) 2}$ adjacent hydrogen $(\mathrm{s}), 555 v_{(\mathrm{N}-\mathrm{Pt})}(\mathrm{s}), 439 v_{(\mathrm{S}-\mathrm{Pt})}(\mathrm{s})$.

\section{Preparation of complex $\left[\mathrm{Pt}\left(\mathrm{L}^{4}\right) \mathrm{Cl}_{2}\right]$ (IV)}

The above-named product was synthesized using potassium tetrachloroplatinate salt $\left(\mathrm{K}_{2} \mathrm{PtCl}_{4}\right)(0.103 \mathrm{~g}, 0.25 \mathrm{mmol})$ and ligands $\left(\mathbf{L}^{4}\right)(0.117 \mathrm{~g}, 0.25 \mathrm{mmol})$ in $1: 1$ ratio, after reflux for 6 $\mathrm{h}$ in $\mathrm{MeOH} / \mathrm{H}_{2} \mathrm{O}$ system as described in general process. Colour: brown powder, yield: $85 \%$, mol. wt: $734.78 \mathrm{~g} \mathrm{~mol}^{-1}$, m.p.: $>300{ }^{\circ} \mathrm{C}$; anal. calc. (\%) for $\mathrm{C}_{22} \mathrm{H}_{15} \mathrm{BrCl}_{3} \mathrm{~N}_{3} \mathrm{PtS}$ : C, 35.56; $\mathrm{H}$, 2.26; N, 5.42; Pt, 26.28; S, 4.86. Found (\%): C, 35.45; H, 2.19; $\mathrm{N}, 5.37$; Pt, 26.36; S, 4.52. Conductance: $22 \Omega^{-1} \mathrm{~cm}^{2} \mathrm{~mol}^{-1}$. UV-vis: $\lambda(\mathrm{nm})\left(\varepsilon, \mathrm{M}^{-1} \mathrm{~cm}^{-1}\right): 265$ (35 120), 303 (21620), 378 (19600). ${ }^{1} \mathrm{H}$ NMR (400 MHz, DMSO-d ${ }_{6}$ ) $\delta /$ ppm: 3.285 (1H, dd, $\left.{ }^{3} J_{1}=10.00 \mathrm{~Hz},{ }^{3} J_{2}=9.6 \mathrm{~Hz}, \mathrm{H}-\mathrm{a}\right) 4.125\left(1 \mathrm{H}, \mathrm{dd},{ }^{3} J_{1}=12.4 \mathrm{~Hz}\right.$, $\left.{ }^{3} J_{2}=5.2 \mathrm{~Hz}, \mathrm{H}-\mathrm{b}\right), 5.732\left(1 \mathrm{H}, \mathrm{dd},{ }^{3} J_{1}=9.6 \mathrm{~Hz},{ }^{3} J_{2}=7.6 \mathrm{~Hz}\right.$,

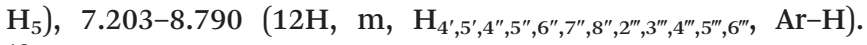
${ }^{13} \mathrm{C}$ NMR (100 MHz, DMSO-d6) $\delta / \mathrm{ppm}$ : 155.13 ( $\left.\mathrm{C}_{2^{\prime \prime}}, \mathrm{C}_{\text {quat. }}\right)$, $153.19\left(\mathrm{C}_{3^{\prime}}, \mathrm{C}_{\text {quat. }}\right), 151.11$ ( $\left.\mathrm{C}_{9^{\prime \prime}}, \mathrm{C}_{\text {quat }}\right), 150.71\left(\mathrm{C}_{5},-\mathrm{CH}\right)$, $149.15\left(\mathrm{C}_{4^{\prime \prime}},-\mathrm{CH}\right), 145.53\left(\mathrm{C}_{5^{\prime}},-\mathrm{CH}\right), 138.23\left(\mathrm{C}_{4^{\prime}},-\mathrm{CH}\right), 135.82$ $\left(\mathrm{C}_{5^{\prime \prime}},-\mathrm{CH}\right), 132.57\left(\mathrm{C}_{5^{\prime} \mathrm{a}}, \mathrm{C}_{\text {quat }}\right), 132.48\left(\mathrm{C}_{3^{\prime \prime}}, \mathrm{C}_{\text {quat. }}\right), 128.62$ $\left(\mathrm{C}_{8^{\prime \prime}},-\mathrm{CH}\right), 127.84\left(\mathrm{C}_{2^{\prime \prime \prime}, 6^{\prime \prime \prime}},-\mathrm{CH}\right), 127.50$ ( $\mathrm{C}_{3^{\prime \prime \prime}, 55^{\prime \prime}}$, Cquat. $), 127.22$ $\left(\mathrm{C}_{4^{\prime \prime \prime}},-\mathrm{CH}\right), 125.92\left(\mathrm{C}_{1^{\prime \prime \prime}}, \mathrm{C}_{\text {quat. }}\right), 121.56\left(\mathrm{C}_{7^{\prime \prime}},-\mathrm{CH}\right), 116.51\left(\mathrm{C}_{6^{\prime \prime}}\right.$, $-\mathrm{CH}), 116.09\left(\mathrm{C}_{4},-\mathrm{CH}_{2}\right), 114.29\left(\mathrm{C}_{2^{\prime}}, \mathrm{C}_{\text {quat. }}\right), 105.02\left(\mathrm{C}_{3}\right.$, $\mathrm{C}_{\text {quat. }}$. [Total signal observed $=20$ : signal of $\mathrm{C}$ and $\mathrm{CH}_{2}=9$ (thiophene- $\mathrm{C}=2$, pyrazole- $\mathrm{C}=1$, phenyl ring- $\mathrm{C}=1$, quinoline- $\mathrm{C}=4$, pyrazole- $\mathrm{CH}_{2}=1$ ), signal of $\mathrm{CH}=11$ (thiophene- $\mathrm{CH}=2$, pyrazole- $\mathrm{CH}=1$, phenyl ring- $\mathrm{CH}=3$, quinoline-CH $=5]$. FT-IR: $(\mathrm{KBr})\left(\mathrm{cm}^{-1}\right): 3163 v_{(=\mathrm{C}-\mathrm{H}) \mathrm{ar}}(\mathrm{w})$, 1596-1566 $v_{(\mathrm{C}=\mathrm{N})}(\mathrm{s}), 1496-1458 v_{(\mathrm{C}=\mathrm{C}) \text { conjugated alkenes }}(\mathrm{m})$, 1388-1326 $v_{(\mathrm{C}-\mathrm{H}) \text { bonding }}(\mathrm{m}), 1203 v_{(\mathrm{C}-\mathrm{N})}, 1257 v_{(\mathrm{C}-\mathrm{C}) \text { alkanes }}(\mathrm{s})$, $1072 v_{(\mathrm{C}-\mathrm{S}-\mathrm{C}) \text { stre. (thiophene ring) }},(\mathrm{w}), 779-655 v_{(\mathrm{Ar}-\mathrm{H}) 2}$ adjacent hydrogen $(\mathrm{s}), 555 v_{(\mathrm{N}-\mathrm{Pt})}(\mathrm{s}), 509 v_{(\mathrm{S}-\mathrm{Pt})}(\mathrm{s})$.

\section{Preparation of complex $\left[\mathrm{Pt}\left(\mathrm{L}^{5}\right) \mathrm{Cl}_{2}\right](\mathrm{V})$}

The above-named product was synthesized using potassium tetrachloroplatinate salt $\left(\mathrm{K}_{2} \mathrm{PtCl}_{4}\right)(0.103 \mathrm{~g}, 0.25 \mathrm{mmol})$ and ligands $\left(\mathrm{L}^{5}\right)(0.106 \mathrm{~g}, 0.25 \mathrm{mmol})$ in $1: 1$ ratio, after reflux for 6 
$\mathrm{h}$ in $\mathrm{MeOH} / \mathrm{H}_{2} \mathrm{O}$ system as described in general process. Colour: brown powder, yield: $91 \%$, mol. wt: $655.89 \mathrm{~g} \mathrm{~mol}^{-1}$, m.p.: $>300{ }^{\circ} \mathrm{C}$; anal. calc. (\%) for $\mathrm{C}_{22} \mathrm{H}_{16} \mathrm{Cl}_{3} \mathrm{~N}_{3}$ PtS: C, 40.29; H, 2.46; $\mathrm{N}, 6.41 ; \mathrm{Pt}, 29.74 ; \mathrm{S}, 4.89$. Found (\%): C, 40.45; H, 2.39; N, 6.37; Pt, 28.86; S, 4.37. Conductance: $22 \Omega^{-1} \mathrm{~cm}^{2} \mathrm{~mol}^{-1}$. UV-vis: $\lambda(\mathrm{nm})\left(\varepsilon, \mathrm{M}^{-1} \mathrm{~cm}^{-1}\right): 257$ (37 080), 296 (11510), 363 (5470). ${ }^{1} \mathrm{H}$ NMR (400 MHz, DMSO-d ${ }_{6}$ ) $\delta / \mathrm{ppm}: 3.285\left(1 \mathrm{H}, \mathrm{dd},{ }^{3} J_{1}=\right.$ $\left.10.4 \mathrm{~Hz},{ }^{3} J_{2}=8.8 \mathrm{~Hz}, \mathrm{H}-\mathrm{a}\right), 4.122\left(1 \mathrm{H}, \mathrm{dd},{ }^{3} J_{1}=11.6 \mathrm{~Hz},{ }^{3} J_{2}=\right.$ $8.4 \mathrm{~Hz}, \mathrm{H}-\mathrm{b}), 5.731\left(1 \mathrm{H}, \mathrm{dd},{ }^{3} J_{1}=8.0 \mathrm{~Hz},{ }^{3} J_{2}=8.4 \mathrm{~Hz}, \mathrm{H}_{5}\right)$, $7.208-8.793\left(13 \mathrm{H}_{3^{\prime}, 4^{\prime}, 5^{\prime}, 4^{\prime \prime}, 5^{\prime \prime}, 6^{\prime \prime}, 7^{\prime \prime}, 8^{\prime \prime}, 2^{\prime \prime \prime}, 6^{\prime \prime \prime}, 3^{\prime \prime \prime}, 5^{\prime \prime \prime}, 4^{\prime \prime},}, \mathrm{Ar}-\mathrm{H}\right) .{ }^{13} \mathrm{C} \mathrm{NMR}$ (100 MHz, DMSO-d 6 ) $\delta /$ ppm: $155.49\left(\mathrm{C}_{2^{\prime \prime}}, \mathrm{C}_{\text {quat. }}\right), 153.55\left(\mathrm{C}_{3^{\prime}}\right.$, $-\mathrm{CH}), 151.11$ ( $\left.\mathrm{C}_{9 " \text { a }}, \mathrm{C}_{\text {quat. }}\right), 150.21\left(\mathrm{C}_{5},-\mathrm{CH}\right), 149.15\left(\mathrm{C}_{4 "},-\mathrm{CH}\right)$, $145.52\left(\mathrm{C}_{4},-\mathrm{CH}_{2}\right), 138.23\left(\mathrm{C}_{4^{\prime}},-\mathrm{CH}\right), 135.82\left(\mathrm{C}_{5^{\prime \prime}},-\mathrm{CH}\right)$, $132.57\left(\mathrm{C}_{5^{\prime \prime}}, \mathrm{C}_{\text {quat. }}\right), 132.28\left(\mathrm{C}_{3^{\prime \prime}}, \mathrm{C}_{\text {quat. }}\right), 128.62\left(\mathrm{C}_{8^{\prime \prime}},-\mathrm{CH}\right)$, $127.84\left(\mathrm{C}_{2^{\prime \prime \prime}, 6^{\prime \prime \prime}},-\mathrm{CH}\right), 127.50\left(\mathrm{C}_{3^{\prime \prime}, 5^{\prime \prime \prime}},-\mathrm{CH}\right), 127.22\left(\mathrm{C}_{4^{\prime \prime \prime}},-\mathrm{CH}\right)$, $125.92\left(\mathrm{C}_{1^{\prime \prime}}, \mathrm{C}_{\text {quat. }}\right), 121.58\left(\mathrm{C}_{7^{\prime \prime}},-\mathrm{CH}\right), 116.51\left(\mathrm{C}_{6^{\prime \prime}},-\mathrm{CH}\right)$, $116.02\left(\mathrm{C}_{5^{\prime}},-\mathrm{CH}\right), 114.29\left(\mathrm{C}_{2^{\prime}}, \mathrm{C}_{\text {quat. }}\right), 105.02\left(\mathrm{C}_{3}, \mathrm{C}_{\text {quat. }}\right)$. [Total signal observed $=20$ : signal of $\mathrm{C}$ and $\mathrm{CH}_{2}=8$ (thiophene- $\mathrm{C}=$ 1 , pyrazole- $\mathrm{C}=1$, phenyl ring- $\mathrm{C}=1$, quinoline- $\mathrm{C}=4$, pyrazole- $\mathrm{CH}_{2}=1$ ), signal of $\mathrm{CH}=12$ (thiophene- $\mathrm{CH}=3$, pyrazole- $\mathrm{CH}=1$, phenyl ring- $\mathrm{CH}=3$, quinoline- $\mathrm{CH}=5$ ] FT-IR: $(\mathrm{KBr})\left(\mathrm{cm}^{-1}\right): 3124 v_{(=\mathrm{C}-\mathrm{H}) \text { ar }}(\mathrm{w}), 1604-1566 v_{(\mathrm{C}=\mathrm{N})}(\mathrm{s})$, 1504-1465 $v_{(\mathrm{C}=\mathrm{C}) \text { conjugated alkenes }}(\mathrm{m}), 1396-1326 v_{(\mathrm{C}-\mathrm{H}) \text { bonding }}$ $(\mathrm{m}), 1211 v_{(\mathrm{C}-\mathrm{N})}, 1272 v_{(\mathrm{C}-\mathrm{C}) \text { alkanes }}(\mathrm{s}), 1049 v_{(\mathrm{C}-\mathrm{S}-\mathrm{C}) \text { stre. (thiophene }}$ ring) $(\mathrm{w}), 756-671 v_{(\mathrm{Ar}-\mathrm{H}) 2}$ adjacent hydrogen $(\mathrm{s}), 563 v_{(\mathrm{N}-\mathrm{Pt})}(\mathrm{s}), 439$ $v_{(\mathrm{S}-\mathrm{Pt})}(\mathrm{s})$.

\section{Biological application of the compounds}

In vitro antibacterial study. The antibacterial activity of the compounds (free ligands and platinum complexes) was investigated using five test organisms including two $\mathrm{Gram}^{(+\mathrm{ve})}$ species (Bacillus subtilis and Serratia marcescens) and three Gram $^{(-\mathrm{ve})}$ species (Escherichia coli, Pseudomonas aeruginosa and Staphylococcus aureus) using the broth dilution technique. A preculture of bacteria was grown in Luria Broth. DMSO was used as medium to acquire the preferred concentration of the compounds to study their effect on microbial strains. The test compounds at specific concentrations were added to a sugar tube containing Luria Broth as a solution and were sterilized in an autoclave before the addition of the previously cultured bacterial species. After adding different bacterial species to the tubes containing specific concentrations of test compounds, they were allowed to incubate for 24 $\mathrm{h}$, at an optimum temperature. The experiment was repeated till only a faint turbidity appeared in the tube. The lowest concentration at which no growth of bacteria occurred after $24 \mathrm{~h}$ culture was considered as the MIC for each compound. ${ }^{19,20}$

In vitro cytotoxicity (brine shrimp lethality) bioassay. Cytotoxicity assays are widely used by the pharmaceutical industry to screen for cytotoxicity in compound libraries. Brine shrimp (Artemia cysts) eggs were hatched in a shallow rectangular plastic dish $(22 \times 32 \mathrm{~cm})$, filled with artificial seawater, which was prepared with commercial salt mixture and double distilled water. An unequal partition was made in the plastic dish with the help of a perforated device. Approximately 50 $\mathrm{mg}$ of eggs were sprinkled into the large compartment and it was opened to ordinary light. After two days, nauplii were collected by a pipette from the lighted side. The experiment was carried out following the protocol of Mayer et al. A set of 2, 4, $8,16,20 \mu \mathrm{g} \mathrm{mL}^{-1}$ solutions in test tubes was prepared from a stock solution of $1000 \mu \mathrm{g} \mathrm{mL} \mathrm{mL}^{-1}$ of the test compounds. The final volume in each test tube was adjusted to $2500 \mu \mathrm{L}(1000$ $\mu \mathrm{L}$ sea salt solution, $450 \mu \mathrm{L}$ double distilled water, $50 \mu \mathrm{L}$ DMSO + complex and the remaining $1000 \mu \mathrm{L}$ was added as 10 nauplii in a sea salt solution). After $24 \mathrm{~h}$ the numbers of dead nauplii were counted and from this the survival $\mathbf{L C}_{50}$ was calculated. ${ }^{21,22}$

\section{Bioassay of Schizosaccharomyces pombe cells at cellular level}

A cellular level bioassay was carried out using Schizosaccharomyces pombe cells. The detailed process of measuring the cellular level cytotoxicity of the synthesized compounds is described in the literature. ${ }^{23}$

In vitro antiproliferative cytotoxicity on MCF-7 and HCT116 cancer cells. The antiproliferative cytotoxicity of the synthesized Pt(II) complexes (I-V) was determined by the MTT (3-(4,5-dimethyl-2-thiazolyl)-2,5-diphenyl-2H-tetrazolium bromide) assay. The MCF-7 and HCT-116 cells were plated at 5000 cells per well in 96-well culture plates with a culture medium, and incubated for $24 \mathrm{~h}$ at $37{ }^{\circ} \mathrm{C}$ in a $5 \% \mathrm{CO}_{2}$ incubator. The concentrations of compounds included the vehicle control (0.8\% DMSO), DMSO, 50, 100, 250, 500, 1000, 2000 $\mu \mathrm{g} \mathrm{mL} \mathrm{m}^{-1}$. The cells were washed twice with Dulbecco's phosphate-buffered saline (DPBS) and $0.5 \mathrm{mg} \mathrm{mL}^{-1}$ MTT solution and incubated for $4 \mathrm{~h}$ at $37^{\circ} \mathrm{C}$. Subsequently, $0.1 \mathrm{~mL}$ of SDS- $\mathrm{HCl}(10 \%$ SDS in $0.01 \mathrm{M} \mathrm{HCl})$ was added to each well, mixed carefully and allowed to incubate in the dark for 20 $\min$ at $37{ }^{\circ} \mathrm{C}$. Finally, the absorbance of each well was recorded at $570 \mathrm{~nm}$ with a reference wavelength of $650 \mathrm{~nm}$ using a multimedia micro plate reader (Spectra Max M2e, Molecular Devices, USA). IC $_{50}$ values were calculated from the chart of the cell proliferation (\%) against the compound concentration $\left(\mu \mathrm{g} \mathrm{mL}{ }^{-1}\right)$. The results are represented as percentage of cell proliferation in different treatment groups. All experiments were carried out in triplicate. ${ }^{24}$ Cell viability was evaluated by trypan blue exclusion assay. MCF-7 and HCT116 cells were treated with 50, 100, 250, 500, 1000, $2000 \mu \mathrm{g}$ $\mathrm{mL}^{-1}$ of conjugates of complexes (I-V) for $24 \mathrm{~h}$. After completion of incubation, cells were harvested and washed once with DPBS. An equal amount of cell suspension was mixed with trypan blue. Subsequently, live and dead cells were counted and percentage of cell death was determined by the following formula (Percentage of cell death $=$ Number of dead cells/Total number of cells $\times 100$ ). Generally, the complexes showed strong growth inhibitory activity against the cell lines. The complexes have been evaluated for cell proliferation potential in MCF-7 (human breast adenocarcinoma) and HCT-116 (human colon carcinoma) cells and the $\mathrm{IC}_{50}$ values of the complexes were determined by MTT assay. 


\section{Biomolecule (DNA) interaction studies}

(a) Absorption titration spectroscopy. Electronic absorption titration was used to study the relative binding mode of HSDNA with the molecules. Stock solutions of HS-DNA were prepared in phosphate buffer and stored for less than 4 days at 4 ${ }^{\circ} \mathrm{C}$. The UV absorbance of HS-DNA obtained at 260 and $280 \mathrm{~nm}$ in phosphate buffer $\left(\mathrm{Na}_{2} \mathrm{HPO}_{4} / \mathrm{NaH}_{2} \mathrm{PO}_{4}, \mathrm{pH}=7.2\right)$ solution at room temperature gave a ratio of $1.8-1.9: 1$, signifying that the DNA was suitably free from proteins. ${ }^{25}$ The molar absorption coefficient $(\varepsilon)$ of HS-DNA was taken as $12858 \mathrm{M}^{-1} \mathrm{~cm}^{-1}$. These experiment were performed by maintaining a constant concentration of complexes and varying the concentration of HS-DNA. Complex-DNA solutions were allowed to incubate for $10 \mathrm{~min}$ at room temperature before measurements were taken. While measuring the absorption spectra, an equal quantity of HSDNA was added to both the complex solution and the reference solution to eliminate the absorbance of HS-DNA itself.

(b) Viscosity measurements. Viscosity experiments were performed by using an Ubbelohde viscometer (maintained at a constant temperature of at $25.0 \pm 0.5^{\circ} \mathrm{C}$ in a thermostatic jacket in a water bath). The viscosity of a $200 \mu \mathrm{M}$ solution of HS-DNA was determined in the presence of the complexes using different [complex]/[DNA] ratios in the range of 0.00 to 2.00. The flow time was measured in triplicate by digital stopwatch and then averaged (where $\eta$ and $\eta_{0}$ were the relative viscosity of DNA in the presence or absence of complexes, respectively). The hydrodynamic length of DNA generally increases upon partial intercalation while it does not lengthen upon groove binding. ${ }^{26}$ Viscosity measurements can sensitively detect the lengthening of a DNA helix induced by the binding of intercalators and thus provide evidence of intercalation for small DNA-binding molecules. ${ }^{27}$ The data are represented as the plot of the relative viscosity, i.e. $\left(\eta / \eta_{0}\right)^{1 / 3}$ vs. [complex]/[DNA $] .{ }^{12}$

(c) Molecular modeling study. Docking studies were performed for the $\mathrm{Pt}$ (II) complexes with a biomolecule (DNA), to identify the binding mode of the metal complexes and the vital functional groups interacting with the DNA, using Hex 8.0 software. The detailed process of this study is described in the literature. ${ }^{28}$

(d) Fluorescence quenching analysis. Emission intensity measurements of ethidium bromide ( $\mathrm{EB}=3,8$-diamino-5ethyl-6-phenylphenanthridinium bromide) with free HS-DNA in the absence and presence of $\mathrm{Pt}$ (II) complexes were performed in phosphate buffer. The HS-DNA solution was prepared with the value of $r=3.33$ ([DNA]/[complex]) of pretreated EB-DNA mixture $([\mathrm{EB}]=33.3 \mu \mathrm{M},[\mathrm{DNA}]=10 \mu \mathrm{M})$ at ambient temperature and incubated for $10 \mathrm{~min}$ before measurement. The emission intensity was recorded in the range of $500-800 \mathrm{~nm}$. The emission intensities at $610 \mathrm{~nm}\left(\lambda_{\max }\right)$ were obtained through excitation at $510 \mathrm{~nm}$ and slit wavelength $1.45 \mathrm{~nm}$ in the FluoroMax-4, HORIBA (Scientific) spectrofluorometer. The changes in fluorescence intensities of ethidium bromide when bound to DNA were measured with respect to different concentrations of the complex. Ethidium bromide has lower emission intensity in phosphate buffer solution at $7.2 \mathrm{pH}$ due to florescence quenching of free ethidium bromide by the solvent molecules. In the presence of DNA, EB exhibits higher intensity due to its partial intercalative binding mode to DNA. Fluorescence quenching of an EB-DNA mixture can arise owing to the inner-filter effect. The mechanism of quenching can be deduced from the emission intensity of EB. In our study, the inner filter effect was corrected with the following equation obtained from the literature. ${ }^{5,29}$

The Stern-Volmer quenching constant $\left(K_{\text {sv }}\right)$ was determined by eqn (1): ${ }^{30,31}$

$$
I^{0} / I=K_{\mathrm{sv}}[\mathrm{Q}]+1
$$

where $I_{0}$ and $I$ are the emission intensity of EB-DNA in the absence and presence of quencher (complex), $K_{\mathrm{sv}}$ is the linear Stern-Volmer quenching constant obtained from the plot of $I_{0} / I$ vs. [Q] and [Q] is the concentration of quencher. To determine the strength of the interaction of complexes with DNA, the value of the associative binding constant $\left(K_{\mathrm{a}}\right)$ was calculated using the Scatchard equation (eqn (2)): ${ }^{13,32}$

$$
\log I_{0}-I / I=\log K_{\mathrm{a}}+n \log [\mathrm{Q}]
$$

where $I_{0}$ and $I$ are the fluorescence intensities of the EB-DNA in the absence and presence of different concentrations of complexes, respectively, and $n$ is the number of binding pairs. The forces acting between drugs and biomacromolecules include hydrogen bonds, van der Waals forces, electrostatic attraction and hydrophobic interaction, etc. In order to estimate the interaction force of the various compounds, the standard free energy changes $(\Delta G)$ for the binding process have been calculated using the Van't Hoff equation (eqn (3)): ${ }^{33}$

$$
\Delta G^{0}=-R T \ln K_{\mathrm{a}}
$$

where $T$ is the temperature $\left(25^{\circ} \mathrm{C}, 298 \mathrm{~K}\right.$ here $), K_{\mathrm{a}}$ is the associative binding constant and $R$ is the gas constant $(8.314 \mathrm{~J}$ $\mathrm{mol}^{-1} \mathrm{~K}^{-1}$ ). A negative sign for $\Delta G^{0}$ means that the binding process is spontaneous. $^{34}$

\section{Chemical nuclease activity}

A gel electrophoresis study was performed using pUC19 DNA with the synthesized compounds. The samples were incubated for $0.5 \mathrm{~h}$ at $37^{\circ} \mathrm{C}$. The samples were analysed by $1 \%$ agarose gel electrophoresis (Tris-acetate-ethylenediaminetetraacetic acid [TAE] buffer, $\mathrm{pH}$ 8.0) for $3 \mathrm{~h}$ at $100 \mathrm{mV}$. The gel was stained with $\left(0.5 \mathrm{mg} \mathrm{mL}^{-1}\right)$ ethidium bromide. The gels were viewed in the Alpha Innotech Corporation Gel Doc System and photographed using a CCD (charged coupled device) camera. The cleavage efficiency of the compounds and the degree of DNA cleavage activity were measured by determining the ability of the complexes to convert from SC-DNA to OC-DNA, using an equation described in the literature. ${ }^{35,36}$ 


\section{Results and discussion}

\section{NMR spectroscopy}

The ${ }^{1} \mathbf{H}$ NMR spectra of the free ligands $\left(\mathbf{L}^{1}-\mathbf{L}^{5}\right)$, containing a pyrazole ring, show a doublet of doublet proton signals $\left(\mathrm{H}_{4 \mathrm{a}}\right.$ $4 \mathrm{~b}, 5)$ in the range of 5.769-3.255 ppm, and the multiplet protons of heteroaromatic and arene rings appear in the range of 8.067-6.754 ppm. Upon complexation, $\mathrm{H}_{4 \mathrm{a}} 4 \mathrm{~b}, \mathrm{H}_{5}$ and aromatic protons are shifted up field in the range of 5.753-3.251 ppm and 7.201-8.799 ppm, respectively. On the other hand the ${ }^{13} \mathrm{C}$ NMR spectra of the free ligands, containing $\left(\mathrm{C}_{2^{\prime}}\right)$ carbon atoms of thiophene rings, contain signals in the range of 144.73-144.83 ppm, while in complexes these signals are shifted up field in the range of 114.29-114.69 ppm. Free pyrazole rings containing the imine carbon $(>\mathrm{C}=\mathrm{N})$ peak are observed in the range of 136.86-136.87 ppm, whereas upon complexation this imine carbon peak is observed in the range of 105.60-105.00 ppm. The ${ }^{1} \mathrm{H}$ and ${ }^{13} \mathrm{C}$ NMR spectra confirmed that the $\mathrm{N}, \mathrm{S}$-donor bidentate ligands are coordinated to the platinum centre to give platinum(II) complexes. The ${ }^{1} \mathrm{H}$ and ${ }^{13} \mathrm{C}$ NMR data of ligands and complexes are represented in the Experimental section and ESI $\dagger$ (1 and 2), respectively.

\section{Fourier transform infrared spectroscopy}

The FT-IR spectra of the 5-quinoline based 1,3,5-trisubstituted pyrazole derivatives of free ligands $\left(\mathbf{L}^{1}-\mathbf{L}^{5}\right)$ show the sharp peak for the pyrazole ring containing $v(>\mathrm{C}=\mathrm{N})$ stretching bands in the range of 1543-1596 $\mathrm{cm}^{-1}$, but for the complexes (I-V), the $v(>\mathbf{C}=\mathbf{N})$ bands are shifted to higher frequencies in the range of $1604-1566 \mathrm{~cm}^{-1} \cdot{ }^{37}$ In the free ligands, the thiophene heterocyclic ring contains $v(\mathrm{C}-\mathrm{S}-\mathrm{C})$ bands, which are observed in the range of 1041-1042 $\mathrm{cm}^{-1}$. This is assigned to the nitrogen atom of the $(>\mathrm{C}=\mathrm{N})$ imine functional group now being coordinated to platinum metal. The unsaturated cyclic alkene $v(=\mathrm{C}-\mathrm{H})$ bands of aromatic stretching frequencies are observed for all the free ligands in the range of $3038-3039 \mathrm{~cm}^{-1}$, while in the platinum(II) complexes these bands are observed at around $3124-3170 \mathrm{~cm}^{-1}$. In the complexes, the $v(\mathrm{Pt}-\mathrm{N})$ and $v(\mathrm{Pt}-\mathrm{S})$ bands appear at around $524-563 \mathrm{~cm}^{-1}$ and $439-509 \mathrm{~cm}^{-1}$, respectively. ${ }^{38}$ The above FT-IR data are illustrated in the Experimental section and the FT-IR data table is shown in ESI 3.†

\section{Mass spectroscopy}

Mass spectral data of the free ligands $\left(\mathbf{L}^{\mathbf{1}}-\mathbf{L}^{5}\right)$ and platinum(II) complex (I) are represented in the Experimental section. Mass spectral graphs of the ligands $\left(\mathbf{L}^{1}-\mathbf{L}^{5}\right)$ and complex (I) are represented in ESI 4. $\dagger$ The mass spectrum of the complex (I) shows peaks at $m / z=690.33,692.30,694.31,696.29$ and 698.32 , due to the presence of four chlorine atoms, and it also confirms that chlorine atoms are attached to the platinum metal atom through covalent bonds. The peak appearing at $m / z=654.88$ is due to loss of one chlorine atom. Some other fragments at $619.43,424.34,347.24,230.67$ and $69.09 \mathrm{~m} / z$ values are observed. The peak at $m / z=424.34$ is the base peak of $100 \%$ intensity.

\section{Thermo-gravimetric analysis}

The complex (I) was studied using thermogravimetric analysis (TGA) to examine the thermal behaviour of the complexes under dinitrogen $\left(\mathrm{N}_{2}\right)$ atmosphere at a scanning rate of $10^{\circ} \mathrm{C}$ $\mathrm{min}^{-1}$. There was no weight loss up to the temperature of 160 ${ }^{\circ} \mathrm{C}$, which indicates the absence of water molecules in the complex. The decomposition temperature profiles of the platinum(II) complexes are divided in two steps, where the first loss $(10.28 \%)$ occurring in the temperature range of 170$220{ }^{\circ} \mathrm{C}$ is related to loss of chlorine molecules $\left(\mathrm{Cl}_{2}\right)$. The second loss $(61.46 \%)$ occurring in the temperature range of 380 $490{ }^{\circ} \mathrm{C}$ corresponds to the decomposition of quinoline based 1,3,5-tri-substituted pyrazole ligands, leaving behind metallic platinum as a residue. ${ }^{39}$ These results suggest that the platinum(II) complexes have high thermostability.

\section{Electronic transition and conductivity measurements}

The electronic spectra of the Pt(II) complexes exhibit three bands in the range of $257-380 \mathrm{~nm}$. The bands in the range of 370-380 $\mathrm{nm}$ correspond to $\mathrm{d}-\mathrm{d}$ transitions. The other band around $295-307 \mathrm{~nm}$ is assigned to the metal-to-ligand charge transfer (MLCT) transitions, while the band around 257-260 $\mathrm{nm}$ is assigned as intraligand charge transfer (ILCT) bands. ${ }^{40}$ The molar conductivities $\left(\Lambda_{\mathrm{m}}\right)$ of the Pt(II) complexes are observed in the range of $18-25 \Omega^{-1} \mathrm{~cm}^{2} \mathrm{~mol}^{-1}$, which indicates the non-electrolytic nature of the complexes.

\section{Biological screening of the compounds}

In vitro antimicrobial study. The in vitro antibacterial activities of the ligands and platinum(II) complexes were tested against five different microorganisms, including two $\operatorname{Gram}^{(+\mathrm{ve})}$ species (Bacillus subtilis and Staphylococcus aureus) and three $\operatorname{Gram}^{(-\mathrm{ve})}$ species (Serratia marcescens, Escherichia coli and Pseudomonas aeruginosa). Antibacterial activity is defined as the lowest concentration which inhibits the growth of microorganisms (MIC), evidenced by lack of turbidity in the tube. The results of antibacterial activity testing are represented in Fig. 1 and the MIC values of the compounds are

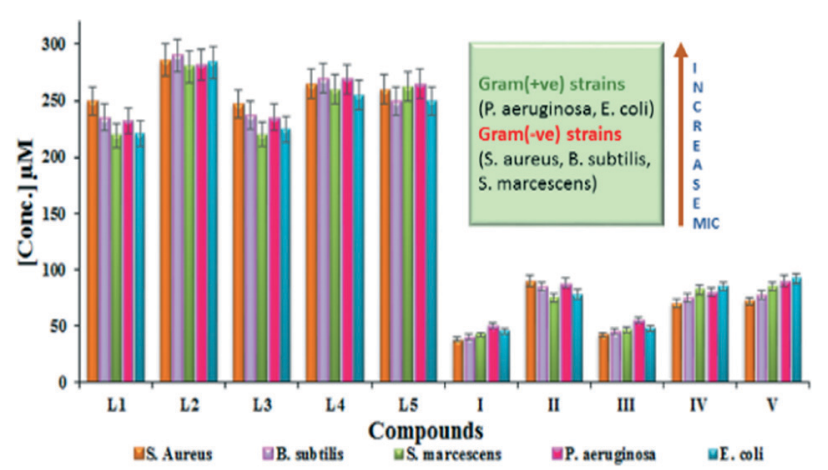

Fig. 1 Antibacterial activity of the ligands $\left(L^{1}-L^{5}\right)$ and platinum(II) complexes (I-V) against five different microorganisms (Bacillus subtilis, Staphylococcus aureus, Escherichia coli, Pseudomonas aeruginosa and Serratia marcescens). Error bars are calculated from three repeated experiments (STD $\pm 5 \%$ ). 


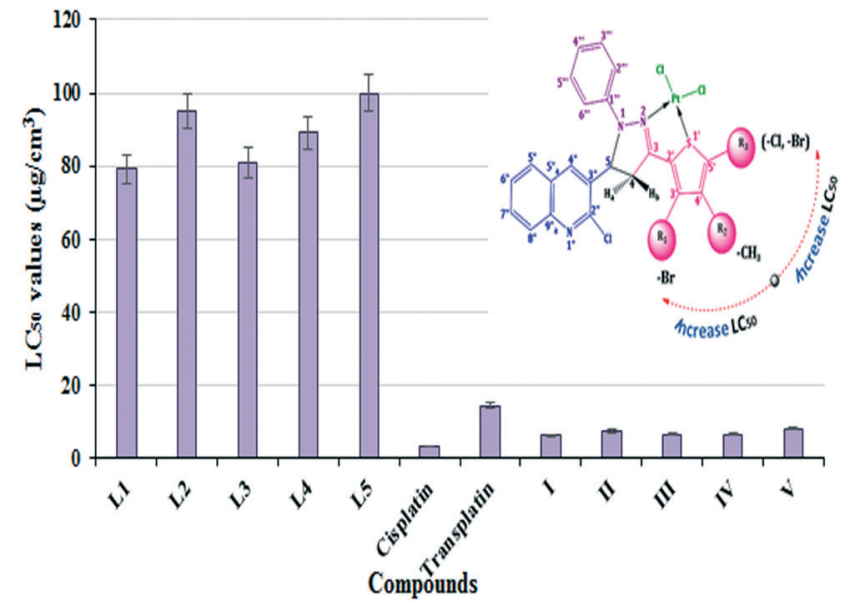

Fig. 2 In vitro cytotoxicity of the platinum(II) complexes (I-V), cisplatin, transplatin and 5-quinoline based 1,3,5-tri-substituted pyrazole derivative ligands $\left(\mathrm{L}^{1}-\mathrm{L}^{5}\right)$.

shown in ESI 5. $\uparrow$ The compounds reveal moderate to strong antibacterial activity. The platinum(II) complexes show higher efficiency than the parent ligands and $\mathrm{K}_{2} \mathrm{PtCl}_{4}$ salt, under identical experimental conditions, which indicates that the complexation improves the activity of the ligands. The platinum(II) complexes with bromo and chloro substituted functional groups show better activity compared to the methyl substituted platinum(II) complexes. This can be explained by Tweedy's chelation theory. ${ }^{41,42}$ On chelation, the delocalization of $\pi$-electrons over the whole chelate ring will be increased, which enhances the penetration of the complexes into lipid membranes, allowing them to rapidly attack the metal binding sites on the enzymes of microorganisms. Platinum(II) complexes may disturb the metabolic processes of the cell and subsequently block the synthesis of proteins, leading to inhibition of the growth of organisms. ${ }^{43}$ Other factors such as solubility, conductivity and dipole moment are also possible reasons for the inhibited growth of bacteria and increased biological activity of the platinum(II) complexes. The platinum(II) complexes show strong activity, particularly against the $\operatorname{Gram}\left({ }^{-\mathrm{ve}}\right)$ bacteria. $^{44}$

In vitro cytotoxicity. In the brine shrimp lethality bioassay, the platinum(II) complexes (I-V), cisplatin, transplatin and quinoline based 1,3,5-tri-substituted pyrazole ligands $\left(\mathbf{L}^{\mathbf{1}}-\mathbf{L}^{\mathbf{5}}\right)$ exhibited excellent results, indicating that the compounds are biologically active. The mortality rate of nauplii increased with increasing concentration of the compounds. The $50 \%$ lethal concentration $\left(\mathrm{LC}_{50}\right)$ values of the ligands, complexes, cisplatin and transplatin are shown in Fig. 2. The $\mathrm{LC}_{50}$ values of the compounds are distributed in the range of 3.133 to $100 \mu \mathrm{g}$ $\mathrm{mL}^{-1}$. The obtained cytotoxic data are represented in ESI 6. $\dagger$

In vitro cellular level cytotoxicity. The cellular level cytotoxicity of the synthesized compounds was established using $S$. pombe cells. The cell death caused by the toxicity of the synthesized compounds could be easily monitored by trypan blue dye as a staining agent. The toxicity was found to vary with the different types of functional group present in the compounds, and also the concentrations of the synthesized ligands and platinum(II) complexes. Complexes I, III and IV were found to be more cytotoxic, while complexes II and $\mathbf{V}$ were found to be less toxic. The platinum(II) complexes are more cytotoxic in nature as compared to the quinoline based 1,3,5-tri-substituted ligands $\left(\mathbf{L}^{\mathbf{1}}-\mathbf{L}^{\mathbf{5}}\right)$. The cytotoxicities of the synthesized platinum(II) complexes are comparable with cisplatin and transplatin drug standards. The in vivo cytotoxicity of the synthesized compounds is in the order of cisplatin $>$ transplatin $>$ I $>$ III $>$ IV $>$ II $>$ V $>\mathbf{L}^{1}>\mathbf{L}^{3}>\mathbf{L}^{4}>\mathbf{L}^{2}>\mathbf{L}^{5}$ (Fig. 3). After 17-20 h of the treatment, a large proportion of the $S$. pombe cells had been killed due to the toxicity of the complexes. Cellular level cytotoxicity data are represented in ESI $7 . \dagger$

\section{Effect of platinum(II) complexes on the degradation of DNA of $S$. pombe cells}

The results of cellular level cytotoxicity stimulated us to discover whether the complexes have any influence on the degradation of DNA or not. ${ }^{45}$ The DNA degradation of $S$. pombe

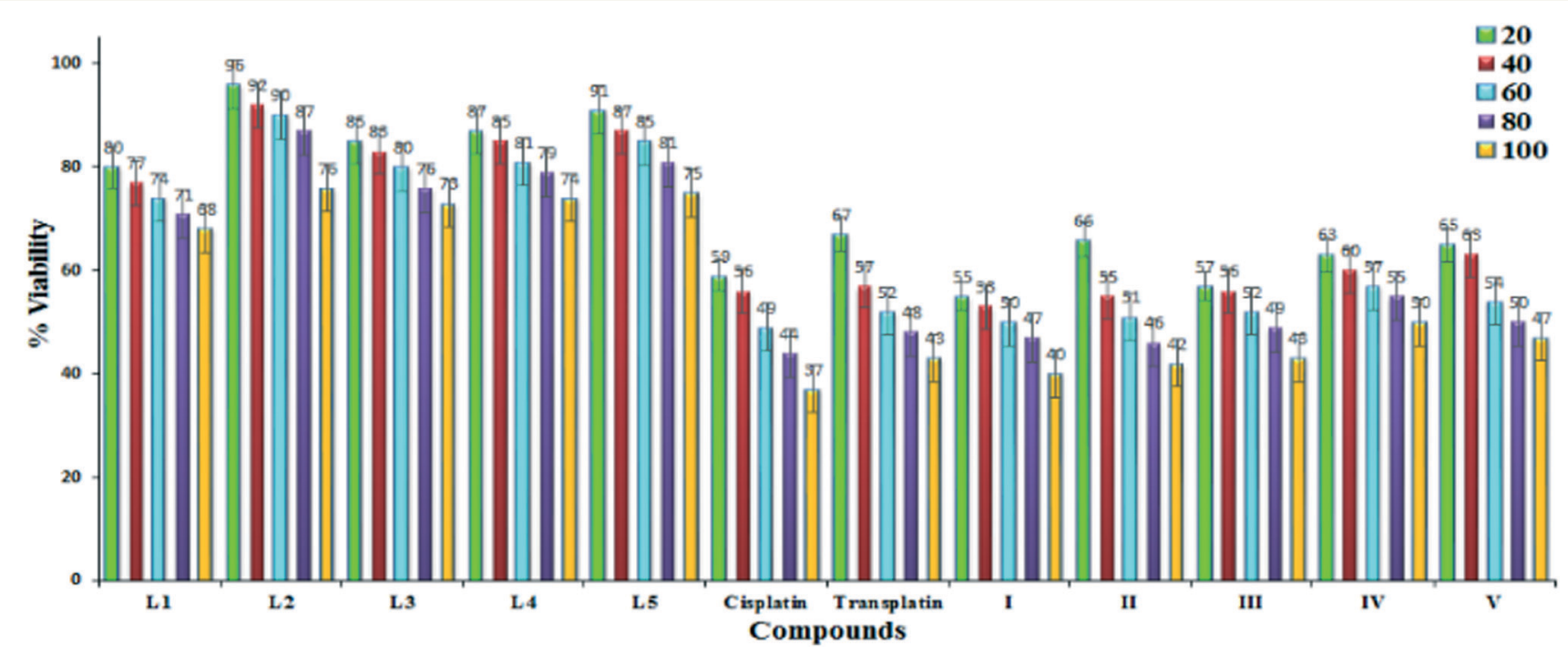

Fig. 3 Influence of compounds on viability of S. pombe cell at different concentration. 


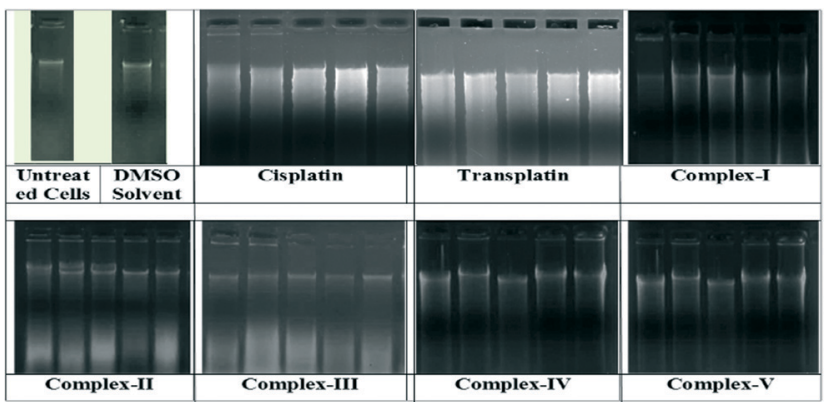

Fig. 4 The DNA damage of the S. pombe cells by treatment with the compounds.

cells was investigated by the comparison of DNA from treated and untreated $S$. pombe cells, and the degradation of the $S$. pombe cells' DNA was also visualized on electrophoresed $1 \%$ agarose gel. When the platinum(II) complexes were used to treat $S$. pombe cells, DNA degradation manifested as smearing, while in untreated $S$. pombe cells, no smearing was observed. The degradation of $S$. pombe cellular DNA by complexes (I-V) is represented in Fig. 4. Smearing of $S$. pombe cellular DNA was observed, indicating that damage had occurred due to the toxic nature of the compounds. The cellular level cytotoxicity results are in agreement with the conclusion that the platinum(II) complexes entered into the $S$. pombe cells and caused the degradation of DNA. Cisplatin, transplatin and the platinum(II) complexes have more cytotoxic potency as compared to the 5-quinoline based 1,3,5-trisubstituted pyrazole derivative ligands.

In vitro antiproliferative cytotoxicity on MCF-7 and HCT116 cancer cells. The positive results observed in DNA binding and DNA cleavage studies directed us to examine the cell growth inhibition of the platinum(II) complexes. To examine the potential of the complexes as antitumor agents,

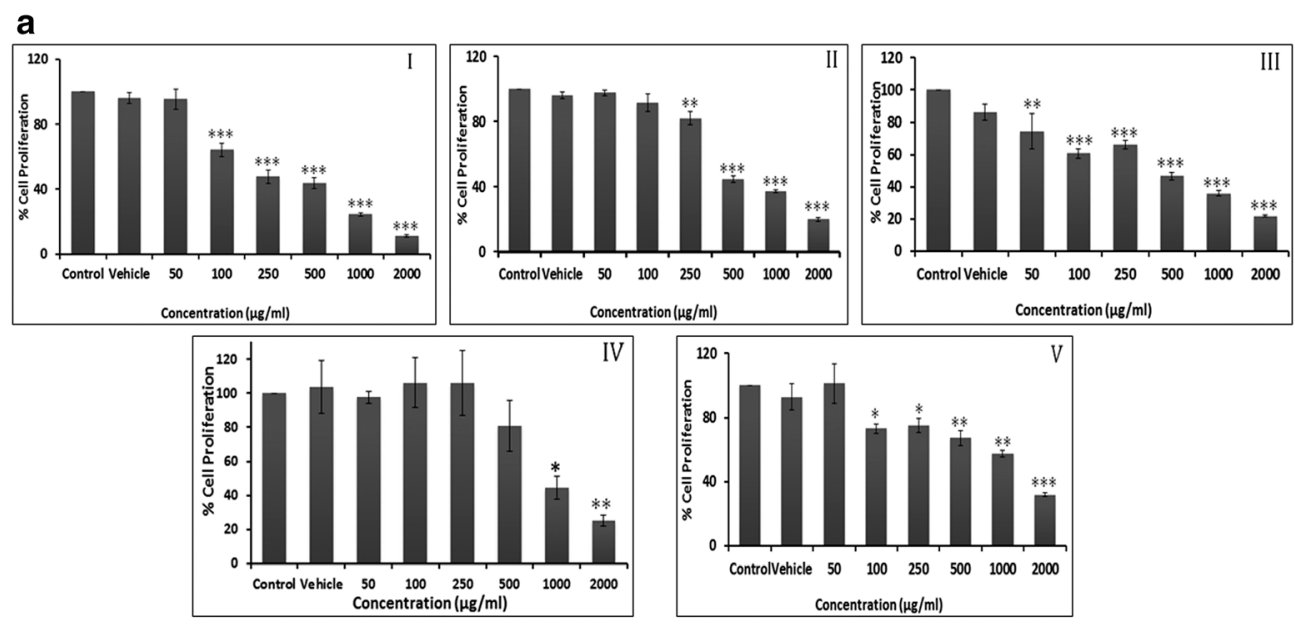

b
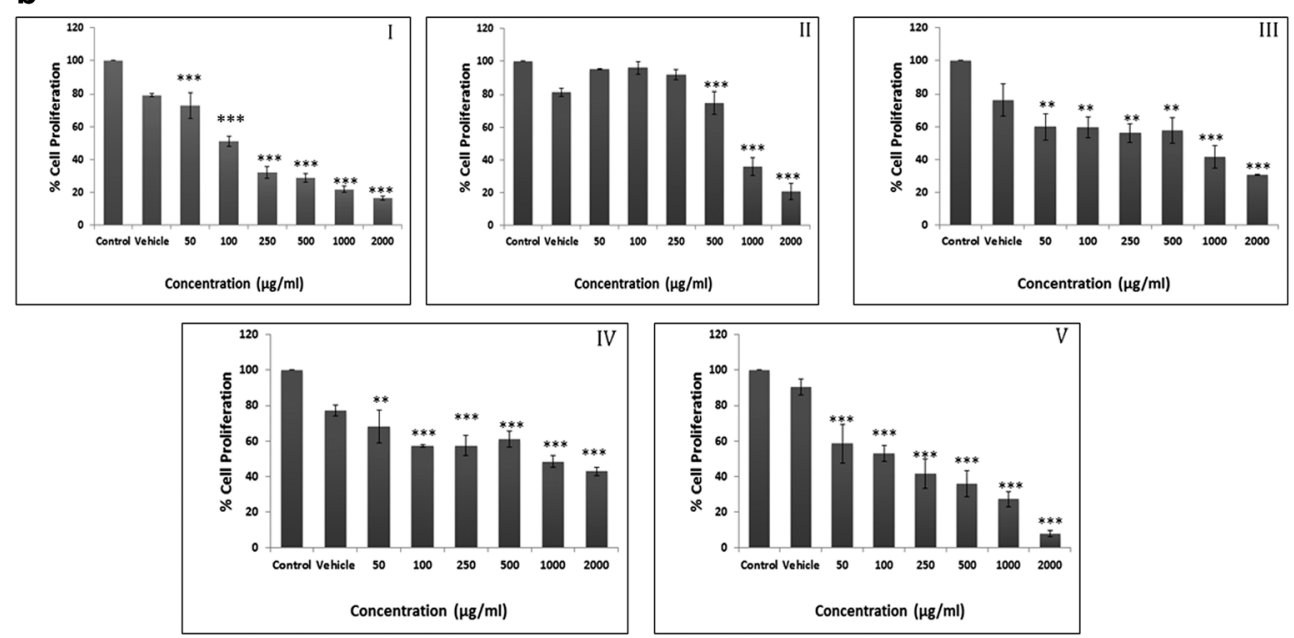

Fig. 5 (a) Effect of conjugates of synthesized Pt(II) complexes on cell proliferation (MTT assay). Determination of $\mathrm{IC}_{50}$ value of conjugates of Pt(II) complexes (I-V) in MCF-7 cancer cell line. Error bars represent mean \pm SEM of three independent experiments. Significant difference indicated as $* P \leq 0.5$ between untreated and complexes-treated cells, $* * P \leq 0.01$. Error bars represent deviation of three replicates. (b) Effect of conjugates of synthesized Pt(II) complexes on cell proliferation (MTT assay). Determination of IC 50 value of conjugates of Pt(II) complexes (I-V) in HCT-116 cancer cell line. Error bars represent mean \pm SEM of three independent experiments. Significant difference indicated as $* P \leq 0.5$ between untreated and complexes-treated cells, $* * P \leq 0.01$. Error bars represent deviation of three replicates. 
the in vitro antiproliferative activity of the synthesized platinum(II) complexes (I-V) against MCF-7 (human breast adenocarcinoma) and HCT-116 cell lines were evaluated by MTT assay (Fig. 5a and b). The platinum(II) complexes ranged in concentration from $50-2000 \mu \mathrm{g} \mathrm{mL}{ }^{-1}$. The viability of cells in the presence of the tested compounds was compared to that observed in the control, and the inhibition growth (\%) was calculated. The $\mathrm{IC}_{50}$ (i.e., the concentration producing $50 \%$ inhibition of growth) was determined and expressed in $\mu \mathrm{g} \mathrm{mL} \mathrm{m}^{-1}$ concentration (Fig. $6 \mathrm{a}$ and $\mathrm{b}$ ). The $\mathrm{IC}_{50}$ values of the platinum(II) complexes I and III exhibit higher inhibitory effect on the MCF-7 cancer cell line, while II, IV and V were found to be moderately effective. The $\mathrm{IC}_{50}$ values of the $\mathrm{Pt}(\mathrm{II})$ complexes $\mathbf{I}$ and $\mathbf{V}$ exhibit higher inhibitory effect on the HCT-116 cancer cell line, while II, III and IV are found to be moderately effective. The Pt(II) complexes I and III, where the 5 th position of the thiophene ring group contains $-\mathrm{Cl}$ and $-\mathrm{Br}$, have greater in vitro cytotoxicity than the complexes
II $\left(-\mathrm{CH}_{3}\right)$, IV $(-3-\mathrm{Br})$ and $\mathbf{V}(-\mathrm{H})$. Furthermore, the $\mathrm{IC}_{50}$ values of the Pt(II) complexes I and III are comparable with standard drugs such as cisplatin (15.49 $\left.\mu \mathrm{g} \mathrm{mL}^{-1}\right),{ }^{46}$ carboplatin $\left.(>111.37 \mu \mathrm{g} \mathrm{mL})^{-1}\right)^{4}$ and oxaliplatin $\left(22.66 \mu \mathrm{g} \mathrm{mL}{ }^{-1}\right) .{ }^{24}$ The IC $_{50}$ values of the complexes I and III are comparable with the standard drugs carboplatin and oxaliplatin. Complex I $(-\mathrm{Cl})$ is the most cytotoxic against MCF-7 cancer cell line as compared to the other complexes. The cytotoxic effect of DMSO on the cells' viability, measured using control solutions of DMSO, is found to be very low. The $\mathrm{IC}_{50}$ values for the MCF-7 cancer cell line of the Pt(II) complexes are found in the order of I $\left(310.54 \mu \mathrm{g} \mathrm{mL}^{-1}\right)>$ III $\left(517.96 \mu \mathrm{g} \mathrm{mL}^{-1}\right)>$ IV (725.39 $\left.\mu \mathrm{g} \mathrm{mL}^{-1}\right)>\mathrm{V}\left(1001.95 \mu \mathrm{g} \mathrm{mL}^{-1}\right)>$ II $(1336.13 \mu \mathrm{g}$ $\left.\mathrm{mL}^{-1}\right)>$ vehicle control $(0.8 \%$ DMSO $)>$ DMSO.

The $\mathrm{IC}_{50}$ values for the HCT-116 cancer cell line of the Pt(II) complexes are found in order of $\mathbf{I}\left(183.78 \mu \mathrm{g} \mathrm{mL}^{-1}\right)>\mathrm{V}(206.83$ $\left.\mu \mathrm{g} \mathrm{mL}{ }^{-1}\right)>$ II $\left(886.71 \mu \mathrm{g} \mathrm{mL}^{-1}\right)>$ III $\left(1981.44 \mu \mathrm{g} \mathrm{mL}{ }^{-1}\right)>$ IV $\left(>2000 \mu \mathrm{g} \mathrm{mL} \mathrm{mL}^{-1}\right)>$ vehicle control $(0.8 \%$ DMSO $)>$ DMSO.
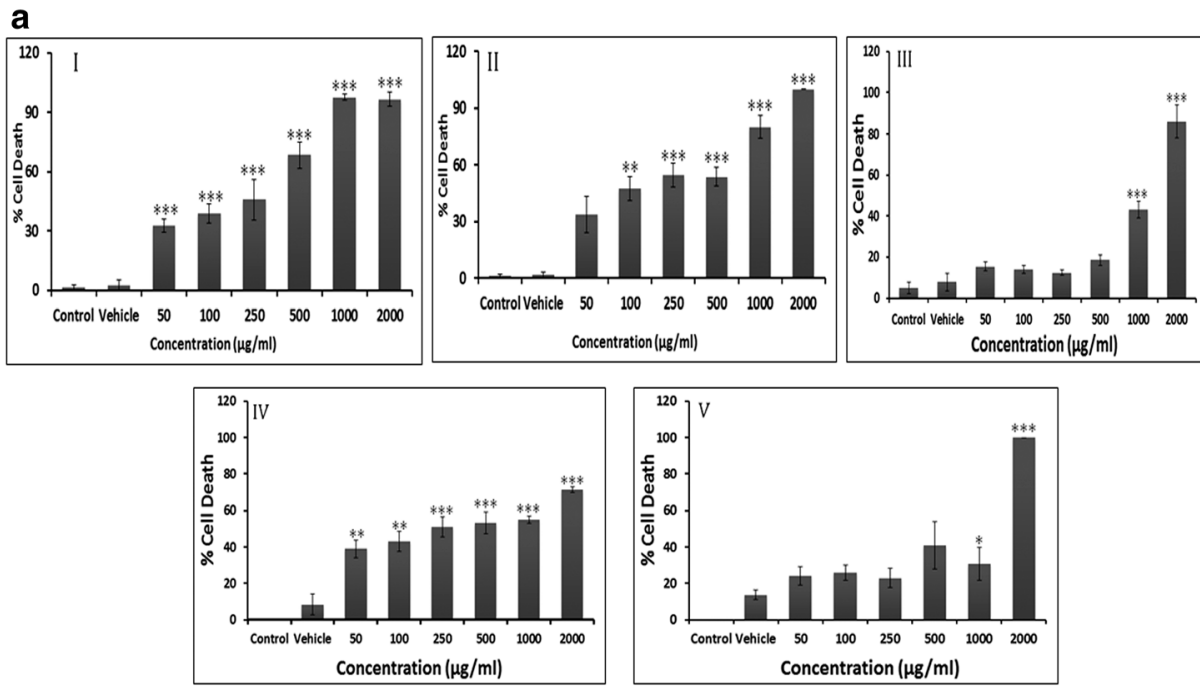

b

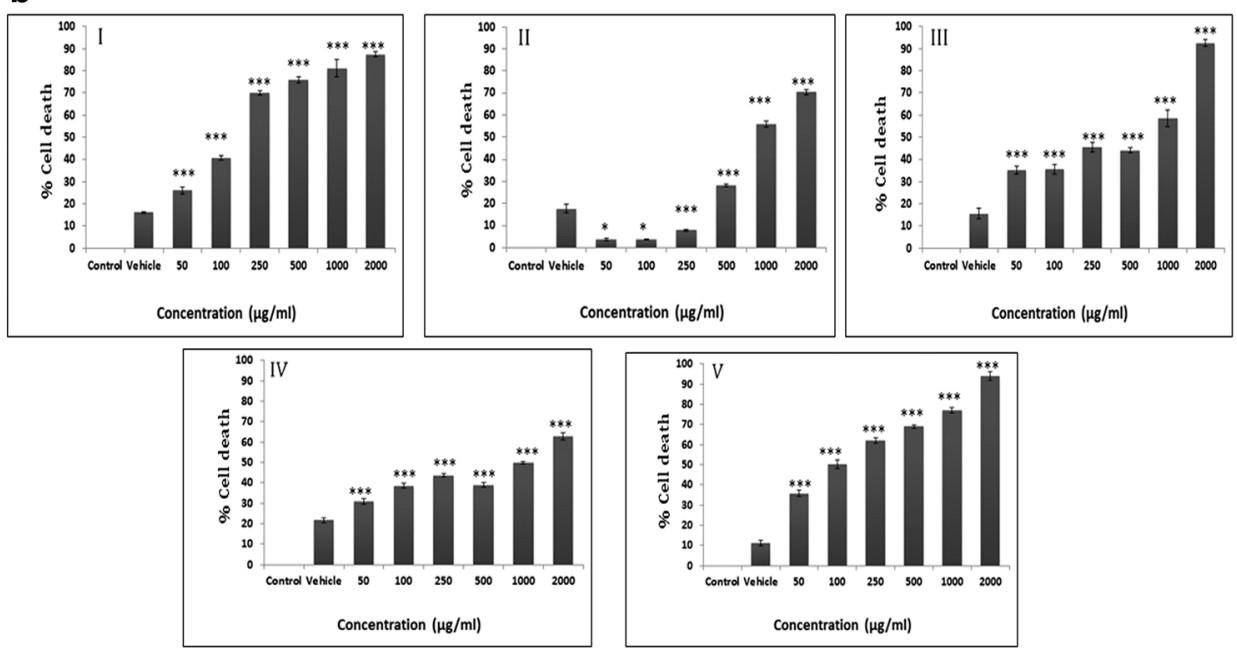

Fig. 6 Evaluation of cell death by trypan blue exclusion assay. Error bars represent mean \pm SEM of three independent experiments. Significant difference indicated as $* p \leq 0.05$ between untreated and complexes-treated cells; $* * p \leq 0.01, * * * p \leq 0.001$. Error bars represent standard deviation of three replicates. 


\section{DNA interaction studies}

(a) Spectral study of the DNA binding. The electronic absorption titration study is one of the most commonly used methods for defining the binding constant $\left(K_{\mathrm{b}}\right)$, binding extent, binding position and size (s) of ligands, and involves monitoring the change in absorption intensity. The binding of compounds with HS DNA via partial intercalation usually results in hypochromism of the absorption intensity and a slight red shift by about 1-3 nm. In general, it is believed that hypochromism and bathochromism are related with the intercalative mode of compounds to the HS DNA helix, involving strong stacking interactions of the planar aromatic rings of the coordinated ligand with the base pairs of DNA. The absorption spectra of the ligand $\left(\mathbf{L}^{\mathbf{1}}\right)$ and complex (I) with and without HS DNA are represented in Fig. 7. The hypochromism of the LMCT absorption band at $310 \mathrm{~nm}$, along with a slight bathochromism, are observed, which indicates the binding of the compounds to DNA by the insertion of an aromatic heterocyclic ligand between adjacent base pairs $(\mathrm{A}=\mathrm{T}$ and $\mathrm{G} \equiv \mathrm{C})$ on the DNA duplex. The extent of the hypochromism is commonly consistent with the strength of the intercalative binding. In order to evaluate the DNA binding strengths of the complexes, the intrinsic binding constants $\left(K_{\mathrm{b}}\right)$ for the association of the complex with HS DNA are obtained from the spectroscopic titration data using the Wolfe-Shimer equation. ${ }^{17}$ The $\%$ hypochromicity $(\% H=$ 17.23-42.67), Gibbs free energy $\left(\Delta G=27.53-31.71 \mathrm{~kJ} \mathrm{~mol}^{-1}\right)$ and binding constant $\left(K_{\mathrm{b}}=0.672-3.618 \times 10^{5} \mathrm{M}^{-1}\right)$ were calculated and the data are represented in Table 1 . The $K_{\mathrm{b}}$ values of cisplatin, oxaliplatin and carboplatin are $5.73 \times 10^{4}$ $\mathrm{M}^{-1},{ }^{47} 5.3 \times 10^{3} \mathrm{M}^{-1}$ (ref. 48 ) and $0.33 \times 10^{3} \mathrm{M}^{-1},{ }^{49}$ respectively and these binding constant $\left(K_{\mathrm{b}}\right)$ values are comparable with the ligands and platinum(II) complexes. The binding abilities of the compounds are in the order of $\mathbf{I}>$ III $>$ IV $>$ II $>\mathbf{V}>\mathbf{L}^{1}>\mathbf{L}^{3}>\mathbf{L}^{4}>\mathbf{L}^{2}>\mathbf{L}^{5}$.

(b) Viscosity measurements assay. Viscosity measurement is a common method to examine the interaction mode between the ligands and platinum(II) complexes with DNA (Fig. 8). Viscosity depends on the shape and size of the HS DNA molecule. The viscosity is obtained from a plot of $(\eta)$ $\left.\eta_{0}\right)^{1 / 3}$, where $\eta$ and $\eta_{0}$ are the specific viscosities of DNA with
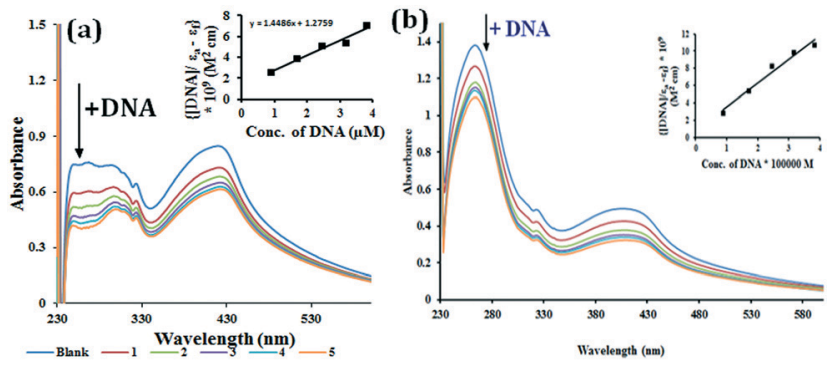

Fig. 7 (a) Absorption spectral traces on addition of HS DNA to ligand ${ }^{\left(L^{1}\right)}\left(K_{b}=1.135 \times 10^{5} \mathrm{M}^{-1}\right)$ with inset plot of [DNA] $/\left(\varepsilon_{\mathrm{a}}-\varepsilon_{\mathrm{f}}\right)$ vs. [DNA]. (b) Absorption spectral traces on addition of HS DNA to complex (I) $\left(K_{\mathrm{b}}=\right.$ $3.618 \times 105 \mathrm{M}^{-1}$ ) with inset plot of [DNA] $/\left(\varepsilon_{\mathrm{a}}-\varepsilon_{\mathrm{f}}\right) v s$. [DNA].
Table 1 The binding constant $\left(K_{\mathrm{b}}, \mathrm{M}^{-1}\right), \%$ hypochromicity and change in Gibbs free energy $\left(\Delta G^{0}, \mathrm{~J} \mathrm{~mol}^{-1}\right)$ of platinum(II) complexes $(\mathrm{I}-\mathrm{V})$ and ligands $\left(L^{1}-L^{5}\right)$ with DNA at different temperatures

\begin{tabular}{|c|c|c|c|c|c|c|}
\hline \multirow[b]{2}{*}{ Compounds } & \multicolumn{2}{|c|}{$\lambda_{\max }(\mathrm{nm})$} & \multirow{2}{*}{$\begin{array}{l}\Delta \lambda \\
(\mathrm{nm})\end{array}$} & \multirow{2}{*}{$\begin{array}{l}K_{\mathrm{b}}\left(\mathrm{M}^{-1}\right) \\
\times 10^{5}\end{array}$} & \multirow[b]{2}{*}{$H \%$} & \multirow{2}{*}{$\begin{array}{l}\Delta G^{0} \\
\left(\mathrm{~J} \mathrm{~mol}^{-1}\right)\end{array}$} \\
\hline & Bound & Free & & & & \\
\hline$L^{1}$ & 324 & 322 & 2 & 1.135 & 30.65 & -28837.8 \\
\hline $\mathbf{L}^{2}$ & 324 & 323 & 1 & 1.012 & 25.96 & -28553.65 \\
\hline $\mathbf{L}^{3}$ & 324 & 323 & 1 & 1.045 & 43.36 & -28633.15 \\
\hline $\mathrm{L}^{4}$ & 325 & 323 & 2 & 1.028 & 31.78 & -28592.52 \\
\hline $\mathbf{L}^{5}$ & 324 & 322 & 2 & 0.672 & 42.67 & -27539.27 \\
\hline I & 265 & 264 & 1 & 3.618 & 20.34 & -31710.23 \\
\hline II & 323 & 322 & 1 & 1.480 & 25.27 & -29495.41 \\
\hline III & 246 & 245 & 2 & 3.308 & 19.57 & -31488.12 \\
\hline IV & 258 & 256 & 2 & 1.600 & 17.23 & -29688.56 \\
\hline V & 300 & 297 & 3 & 1.364 & 17.47 & -29293.19 \\
\hline
\end{tabular}

$H \%=\left[\left(A_{\text {free }}-A_{\text {bound }}\right) / A_{\text {free }}\right] \times 100 \% . K_{\mathrm{b}}=$ Intrinsic DNA binding constant determined from the UV-vis absorption spectral titration. $\Delta \lambda=$ Difference between bound wavelength and free wavelength.

and without the complexes. In general, increasing viscosity suggests that the DNA adopts a more open structure, possibly due to a classical intercalation mode, and causes a bend in the DNA helix reducing its actual length and size. On increasing the amount of the compounds, a significant increasing trend in the relative viscosity of HS-DNA was observed. This suggests that the compounds can bind to the HS-DNA via the partial intercalative mode of binding, which is consistent with the above-mentioned electronic absorption and fluorescence quenching titrations. The relative viscosity order of the synthesized compounds is I $>$ III $>$ IV $>$ II $>$ V $>\mathbf{L}^{\mathbf{1}}>\mathbf{L}^{3}>$ $\mathbf{L}^{4}>\mathbf{L}^{2}>\mathbf{L}^{5}$.

(c) Docking analysis of binding of the ligands and platinum(II) complexes to B-DNA. Molecular docking analysis was performed to discover the binding affinity and mode of binding between the complex-DNA adducts. Slight bending of the DNA occurs in such a way that a part of the planar heterocyclic ring makes a favourable stacking interaction between the DNA base pairs and leads to van der Waals
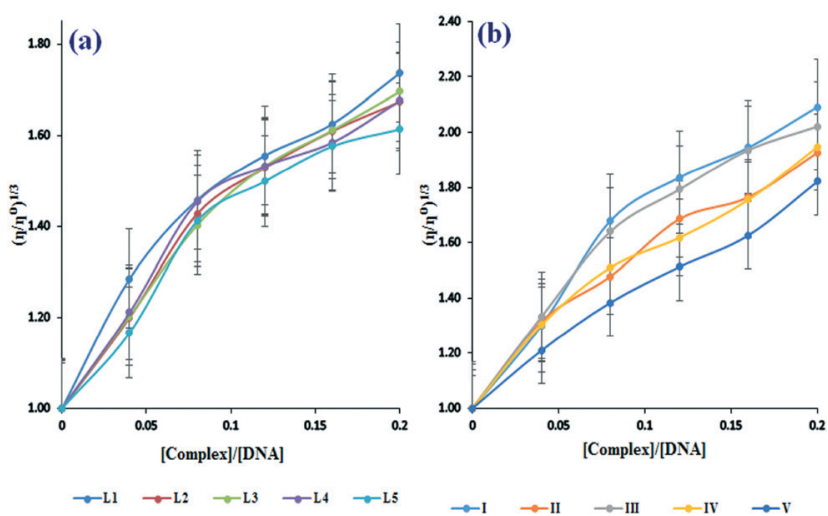

Fig. 8 (a) The relative viscosity graph of synthesized ligands $\left(L^{1}-L^{5}\right)$ with inset plot of $\left(\eta / \eta_{0}\right)^{1 / 3} v s$. [complex]/[DNA]. (b) The relative viscosity graph of synthesized platinum(II) complexes (I-V) with inset plot of $(\eta /$ $\left.\eta_{0}\right)^{1 / 3}$ vs. [complex]/[DNA]. 
interactions and hydrophobic contacts with the B-DNA functional groups that define the groove. ${ }^{50}$ The total energies for binding interaction of the ligands $\left(\mathbf{L}^{1}-\mathbf{L}^{\mathbf{5}}\right)$ and complexes $(\mathbf{I}-\mathbf{V})$ are found to be $-271.68\left(\mathbf{L}^{1}\right),-277.94\left(\mathbf{L}^{2}\right),-275.65\left(\mathbf{L}^{3}\right)$, $-271.37\left(\mathbf{L}^{\mathbf{4}}\right),-266.82\left(\mathbf{L}^{5}\right),-269.82$ (I), -279.38 (II), -284.33 (III), -283.42 (IV), and -265.14 (V). The docking structures of ligand $\left(\mathbf{L}^{\mathbf{1}}\right)$ and complex (I) are shown in Fig. 9 and the docking structures of all the compounds are represented in ESI $8 . \dagger$ This binding study is consistent with the abovementioned fluorescence quenching analysis, viscosity measurement and electronic absorption titration study. (d) Fluorescence quenching analysis (EB exchange) activity. To further examine the mode of binding and binding strength of the platinum(II) complexes with HS-DNA, fluorescence quenching experiments based on the displacement of ethidium bromide (EB) from HS-DNA were performed. These provide evidence about the binding affinity of the complexDNA. ${ }^{51}$ Ethidium bromide is a planar conjugate molecule, which exhibits very weak fluorescence emission intensity in the presence of phosphate buffer solution and in its free state. However, the fluorescence intensity of EB is significantly increased after addition of HS-DNA to the EB-buffer

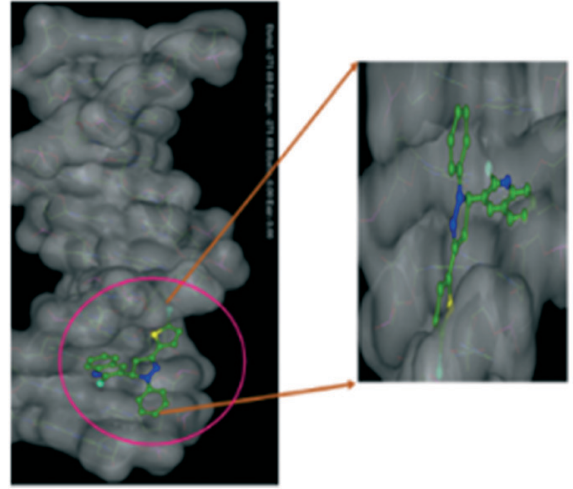

Ligand $\left(\mathrm{L}^{\mathbf{1}}\right)$

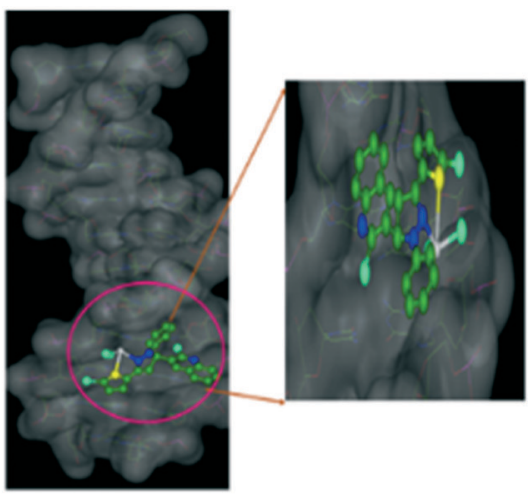

Complex-(I)

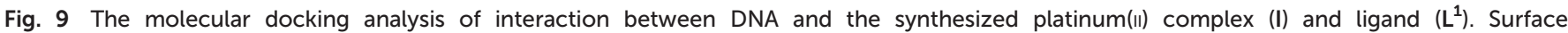
representation of the docked model of complexes with the DNA dodecamer duplex sequence d(CGCGAATTCGCG) 2 (PDB ID: $1 B N A$ ).
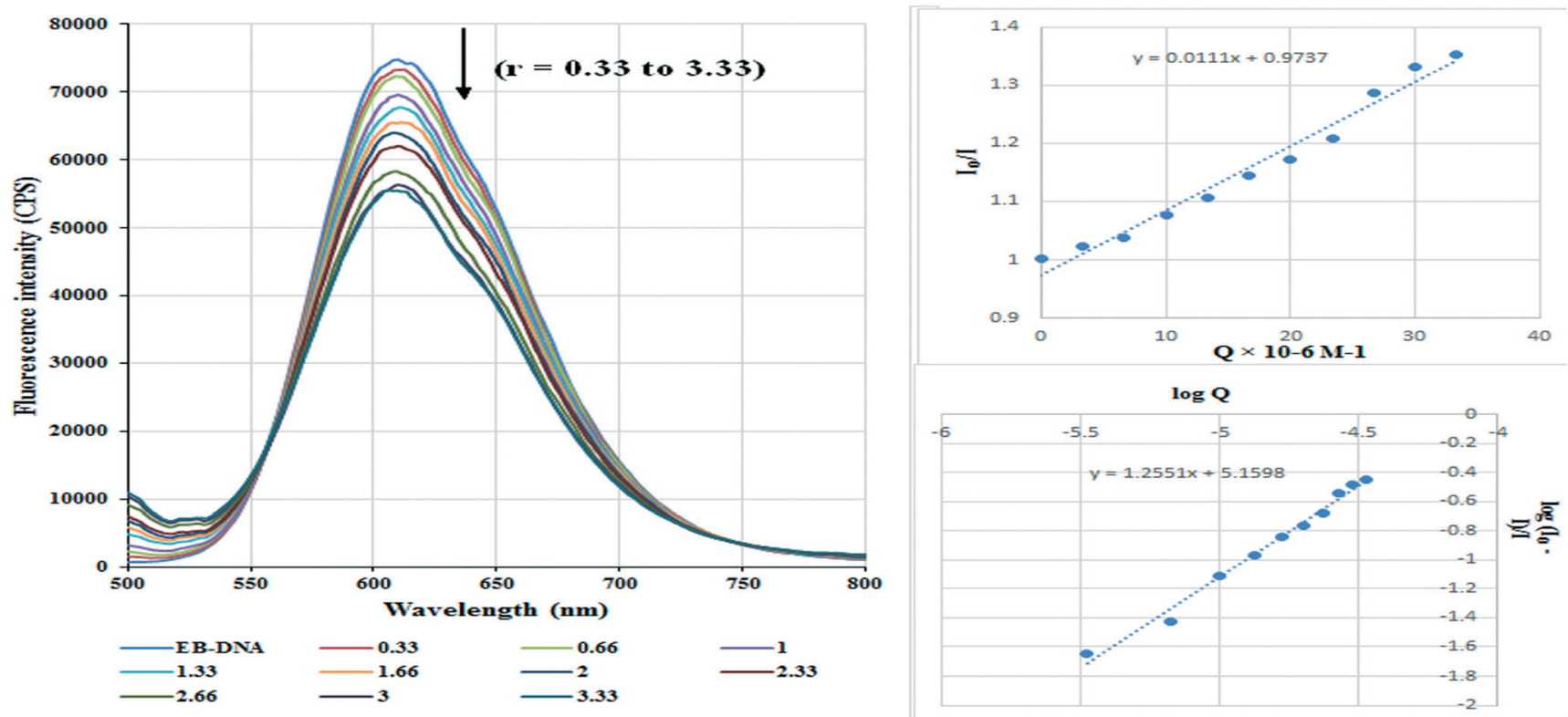

Fig. 10 Fluorescence emission spectra of EB bound to HS-DNA in the presence of complexes (I). [EB] $=33.3 \mu \mathrm{M},[\mathrm{DNA}]=10 \mu \mathrm{M}$; [complex] $=$ (i) 3.33, (ii) 6.66, (iii) 10, (iv) 13.33, (v) 16.66, (vi) 20, (vii) 23.33, (viii) 26.66, (ix) 30, (x) $33.3 \mu \mathrm{M}$; $\lambda_{\mathrm{ex}}=510 \mathrm{~nm}$. The arrows show the intensity changes upon increasing the concentrations of complex. Inset graph: Plots of $I_{0} / / \mathrm{vs}$. [Q], with • for the experimental data points and the dotted line for the linear fitting of the data. Comparative plot of $\log \left[I_{0}-I / I\right]$ versus log[complex] for the titration of HS-DNA EB system with platinum(II) complexes (I) in phosphate buffer medium. 
Table 2 Linear Stern-Volmer quenching constant $\left(K_{\mathrm{sv}}, \mathrm{M}^{-1}\right)$, binding sites (n) and association binding constant $\left(K_{\mathrm{a}}, \mathrm{M}^{-1}\right)$ from competitive binding assay

\begin{tabular}{lllll}
\hline Complexes & $K_{\text {sv }}\left(\mathrm{M}^{-1}\right)$ & $K_{\mathrm{a}}\left(\mathrm{M}^{-1}\right)$ & $n$ & $\Delta G\left(\mathrm{~kJ} \mathrm{~mol}^{-1}\right)$ \\
\hline I & $1.1 \times 10^{2}$ & $1.44 \times 10^{5}$ & 1.25 & -29.435 \\
II & $2.2 \times 10^{3}$ & $0.42 \times 10^{4}$ & 0.84 & -14.991 \\
III & $8.5 \times 10^{3}$ & $1.32 \times 10^{4}$ & 0.84 & -23.563 \\
IV & $5.3 \times 10^{3}$ & $0.77 \times 10^{3}$ & 0.81 & -16.486 \\
V & $3.3 \times 10^{3}$ & $0.15 \times 10^{3}$ & 0.69 & -12.379
\end{tabular}

solution. The intense fluorescence emission is due to the development of the EB-DNA complex. ${ }^{52}$ In this study, the increased concentration of the platinum(II) complexes (I-V) relative to the EB-DNA system caused a reduction of the number of binding sites on the DNA available, together with a decrease in the emission intensity, specifying that these compounds competitively bind to HS DNA. The Stern-Volmer plots and Scatchard plots of the fluorescence quenching analysis of complex-DNA are presented in Fig. 10. The $K_{\mathrm{sv}}$ values for the platinum(II) complexes are found in the range of $1.1 \times 10^{2}-8.5 \times 10^{5} \mathrm{M}^{-1}$. The data of associative binding constant $\left(K_{\mathrm{a}}\right)$ and number of binding sites $(n)$ are listed in Table 2. The associative binding Gibbs free energy of the platinum(II) complexes is found in the range of 29.43-16.48 $\mathrm{kJmol}^{-1}$. Complex (I) exhibits considerably larger binding ability because of the larger number of binding sites present on DNA (Fig. 10). The fluorescence quenching data and emission intensity graph of the complexes $(\mathbf{I}-\mathbf{V})$ are shown in ESI 9.†

\section{Gel electrophoresis}

The ability of the platinum(II) complexes (I-V), cisplatin, transplatin and synthesized ligands $\left(\mathbf{L}^{1}-\mathbf{L}^{5}\right)$ to cleave supercoiled DNA was determined by the agarose gel electrophoresis method. The plasmid pUC19 DNA could be cleaved completely by these compounds, as shown in Fig. 11, and the

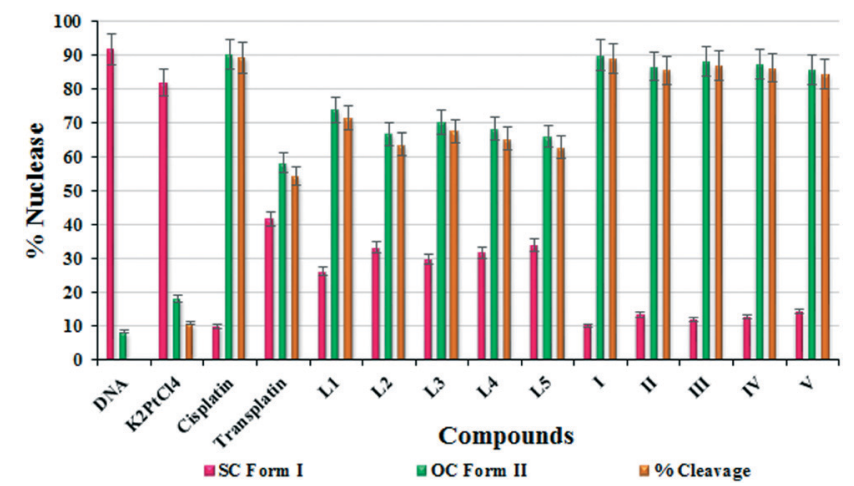

Fig. 11 Photographic images of cleavage of pUC19 DNA (300 $\mu \mathrm{g}$ $\mathrm{cm}^{-3}$ ) with series of ligands $\left(\mathrm{L}^{1}-\mathrm{L}^{5}\right)$ and $\mathrm{Pt}(\mathrm{II})$ complexes $(200 \mu \mathrm{M})$ using $1 \%$ agarose gel containing $0.5 \mu \mathrm{g} \mathrm{cm}^{-3} \mathrm{EtBr}$. Reactions were incubated in TE buffer solution ( $\mathrm{pH} \mathrm{8)}$ at a final volume of $15 \mathrm{~mm}^{3}$ for time period of $3 \mathrm{~h}$ at $37^{\circ} \mathrm{C}$.

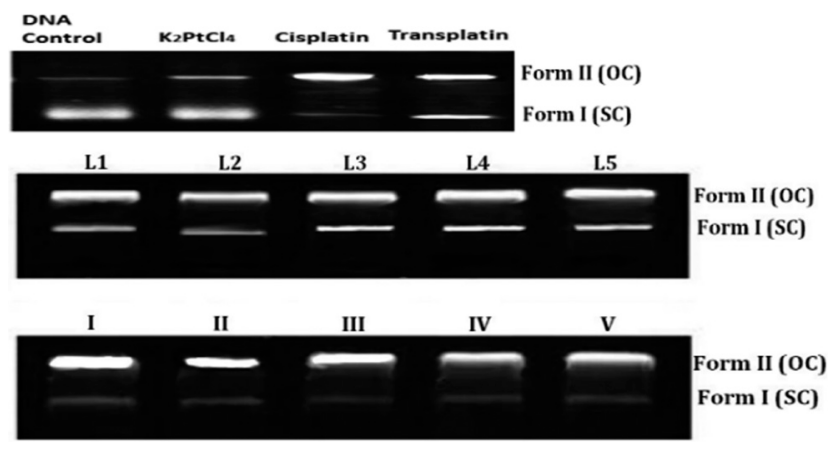

Fig. 12 Plot of nuclease cleavage (\% of form I, form II and DNA cleavage) assay of the ligands $\left(\mathrm{L}^{1}-\mathrm{L}^{5}\right)$ and complexes (I-V). Error bars represent standard deviation of three replicates.

percentage nuclease values of the compounds are represented in ESI 10 $\dagger$ After increasing the complex concentrations, the amount of the supercoiled form of DNA (form I) decreases, while the opened form of DNA (form II) with single-strand breaks increases significantly. The percentage cleavage data of the compounds are represented in Fig. 12. The cleavage efficiency of the compounds is in the order of cisplatin $>$ I $>$ III $>$ IV $>$ II $>$ V $>\mathbf{L}^{1}>\mathbf{L}^{3}>\mathbf{L}^{4}>\mathbf{L}^{2}>\mathbf{L}^{5}>$ transplatin $>\mathrm{K}_{2} \mathrm{PtCl}_{4}$.

\section{Conclusions}

Five new Pt(II) complexes (I-V) with 5-quinoline 1,3,5-trisubstituted pyrazole based ligands $\left(\mathbf{L}^{1}-\mathbf{L}^{5}\right)$ have been synthesized and characterized. The structures of the $\mathrm{Pt}$ (II) complexes $(\mathbf{I}-\mathbf{V})$ and ligands $\left(\mathbf{L}^{1}-\mathbf{L}^{5}\right)$ have been determined by various physicochemical and spectroscopic methods such as microelemental analysis (C, H, N and S), FT-IR, UV-vis, ${ }^{1} \mathrm{H}$ NMR, ${ }^{13} \mathrm{C}$ NMR, TGA, mass spectrometry and molar conductivity. A square planar geometry has been confirmed by UV-visible spectroscopy. The binding constants of the complexes with HS-DNA calculated by UV-visible absorption spectroscopy $\left(K_{\mathrm{b}}\right)$ and fluorescence quenching analysis showed that complexes I, III and IV exhibit a higher binding affinity to DNA than the complexes II and V. The binding ability and binding energy of complex-DNA are higher as compared to ligand-DNA. Furthermore, the compounds bind to HS-DNA via one binding site, as confirmed by the fluorescence titration method. In addition, the percentage DNA cleavage of the complexes I, III and IV is higher than the complexes II and V. Based on the experimental data as well as molecular modeling study, the mode of binding is suggested as partial intercalation and stronger interaction of the complexes to B-DNA than the ligands. Cisplatin, transplatin and the Pt(II) complexes exhibit excellent potency in terms of cellular level cytotoxicity and brine shrimp lethality bioassay compared with the free ligands. The Pt(II) complexes exhibit lower MIC values than the ligands and $\mathrm{K}_{2} \mathrm{PtCl}_{4}$ salt. In addition, the anti-proliferation in vitro cytotoxic activity of the complex $\mathbf{I}$ is more significant as compared to other complexes and the free ligands at 
low concentration against MCF-7 (human breast adenocarcinoma) and HCT-116 (human colon carcinoma) cancer cell lines.

\section{Conflicts of interest}

The authors declare no competing interests.

\section{Acknowledgements}

The authors are thankful to the Head, Department of Chemistry, Sardar Patel University, Vallabh Vidyanagar, Gujarat, India, for providing necessary research facilities, DST-PURSE, Sardar Patel University, Vallabh Vidyanagar for mass spectral analysis. The authors gratefully acknowledge the University Grants Commission, New Delhi, India for meritorious fellowships awarded to them during year 2014-2018 and "BSR UGC One Time Grant", vide UGC letter no. F.19-119/2014 (BSR).

\section{Notes and references}

1 Z. Xi, W. Guo, C. Tian, F. Wang and Y. Liu, Metallomics, 2014, 6, 491-497.

2 N. Kumari, B. K. Maurya, R. K. Koiri, S. K. Trigun, S. Saripella, M. P. Coogan and L. Mishra, MedChemComm, 2011, 2, 1208-1216.

3 S. D. Brown, K. D. Trotter, O. B. Sutcliffe, J. A. Plumb, B. Waddell, N. E. B. Briggs and N. J. Wheate, Dalton Trans., 2012, 41, 11330-11339.

4 C. Icsel, V. T. Yilmaz, Y. Kaya, H. Samli, W. T. Harrison and O. Buyukgungor, Dalton Trans., 2015, 44, 6880-6895.

5 N. J. Wheate, C. R. Brodie, J. G. Collins, S. Kemp and J. R. Aldrich-Wright, Mini-Rev. Med. Chem., 2007, 7, 627-648.

6 T. Meng, S.-F. Tang, Q.-P. Qin, Y.-L. Liang, C.-X. Wu, C.-Y. Wang, H.-T. Yan, J.-X. Dong and Y.-C. Liu, MedChemComm, 2016, 7, 1802-1811.

7 P. N. Yadav, R. E. Beveridge, J. Blay, A. R. Boyd, M. W. Chojnacka, A. Decken, A. A. Deshpande, M. G. Gardiner, T. W. Hambley, M. J. Hughes, L. Jolly, J. A. Lavangie, T. D. MacInnis, S. A. McFarland, E. J. New and R. A. Gossage, MedChemComm, 2011, 2, 274-277.

8 C. J. Adams, M. F. Haddow, R. J. I. Hughes, M. A. Kurawa and A. G. Orpen, Dalton Trans., 2010, 39, 3714-3724.

9 K. Duskova, S. Sierra, M.-J. Fernández, L. Gude and A. Lorente, Bioorg. Med. Chem., 2012, 20, 7112-7118.

10 J. V. Mehta, S. B. Gajera and M. N. Patel, MedChemComm, 2016, 7, 1367-1380.

11 B.-Q. Zou, Q.-P. Qin, Y.-X. Bai, Q.-Q. Cao, Y. Zhang, Y.-C. Liu, Z.-F. Chen and H. Liang, MedChemComm, 2017, 8, 633-639.

12 T. S. Macedo, W. Villarreal, C. C. Couto, D. R. M. Moreira, M. Navarro, M. Machado, M. Prudencio, A. A. Batista and M. B. P. Soares, Metallomics, 2017, 9, 1548-1561.

13 L. Ryckebusch, Z. Wang, N. Bertrand, S.-C. Lin, X. Chi, R. Schwartz, S. Zaffran and K. Niederreither, Proc. Natl. Acad. Sci. U. S. A., 2008, 105, 2913-2918.
14 K. M. El-Gamal, M. S. Hagrs and H. S. Abulkhair, Bull. Fac. Pharm., 2016, 54, 263-273.

15 Z. Wang, J. Yang, Y. Yang, H. Fang, X. Xu, J. Rui, F. Su, H. $\mathrm{Xu}$ and S. Wang, RSC Adv., 2017, 7, 33263-33272.

16 F. Herencia, M. L. Ferrándiz, A. Ubeda, J. Domínguez, J. E. Charris, G. M. Lobo and M. J. Alcaraz, Bioorg. Med. Chem. Lett., 1998, 8, 1169-1174.

17 A. Wolfe, G. H. Shimer and T. Meehan, Biochemistry, 1987, 26, 6392-6396.

18 D. Pucci, A. Bellusci, S. Bernardini, R. Bloise, A. Crispini, G. Federici, P. Liguori, M. F. Lucas, N. Russo and A. Valentini, Dalton Trans., 2008, 5897-5904.

19 S. D. Cummings and R. Eisenberg, J. Am. Chem. Soc., 1996, 118, 1949-1960.

20 J. Luo, Y. Liu, Q. Chen, D. Shi, Y. Huang, J. Yu, Y. Wang, Z. Zhang, G. Lei and W. Zhu, Dalton Trans., 2013, 42, 1231-1237.

21 T. T. Tavares, G. F. Teixeira, C. M. Lopes, W. T. G. Novato, H. Silva, M. T. P. Lopes, M. V. De Almeida, R. M. Grazul, H. F. Dos Santos and A. P. S. Fontes, J. Inorg. Biochem., 2012, 115, 13-19.

22 M. Selvaganapathy, N. Pravin, V. Muniyandi, M. Nazeer and N. Raman, J. Photochem. Photobiol., B, 2016, 157, 77-88.

23 K. G. Samper, S. C. Marker, P. Bayón, S. N. MacMillan, I. Keresztes, Ò. Palacios and J. J. Wilson, J. Inorg. Biochem., 2017, 174, 102-110.

24 J. Zhao, S. Gou, Y. Sun, L. Fang and Z. Wang, Inorg. Chem., 2012, 51, 10317-10324.

25 J. Marmur, J. Mol. Biol., 1961, 3, 208-IN201.

26 S. A. Rosenberg, Nature, 2001, 411, 380.

27 J. D. Hoeschele, T. A. Butler, J. A. Roberts and C. E. Guyer, Radiochim. Acta, 1982, 31, 27-36.

28 T. Sato, H. Awano, O. Haba, H. Katagiri, Y.-J. Pu, T. Takahashi and K. Yonetake, Dalton Trans., 2012, 41, 8379-8389.

29 R. Arora, N. Gill and A. Kapoor, Journal of Pharmacy and Allied Health Sciences, 2014, 4, 15-23.

30 D. Lebwohl and R. Canetta, Eur. J. Cancer, 1998, 34, 1522-1534.

31 T. Boulikas and M. Vougiouka, Oncol. Rep., 2003, 10, 1663-1682.

32 A. Kathiravan and R. Renganathan, Polyhedron, 2009, 28, 1374-1378.

33 M. Hong, G. Chang, R. Li and M. Niu, New J. Chem., 2016, 40, 7889-7900.

34 Ö. Tarı, F. Gümüş, L. Açık and B. Aydın, Bioorg. Chem., 2017, 74, 272-283.

35 A. O. Al-Deeb and A. M. Alafeefy, World Appl. Sci. J., 2008, 5, 94-99.

36 M. Vieites, P. Smircich, M. Pagano, L. Otero, F. L. Fischer, H. Terenzi, M. J. Prieto, V. Moreno, B. Garat and D. Gambino, J. Inorg. Biochem., 2011, 105, 1704-1711.

37 A. Q. Ali, S. G. Teoh, A. Salhin, N. E. Eltayeb, M. B. K. Ahamed and A. M. S. A. Majid, Inorg. Chim. Acta, 2014, 416, 235-244.

38 A. Karaküçük-İyidoğan, D. Taşdemir, E. E. Oruç-Emre and J. Balzarini, Eur. J. Med. Chem., 2011, 46, 5616-5624. 
39 A. A. Soliman, O. I. Alajrawy, F. A. Attaby and W. Linert, J. Mol. Struct., 2016, 1115, 17-32.

40 S. Ray, V. Prajapati, K. Patel and U. Trivedi, Int. J. Biol. Macromol., 2016, 86, 741-749.

41 C. S. Allardyce, P. J. Dyson, D. J. Ellis, P. A. Salter and R. Scopelliti, J. Organomet. Chem., 2003, 668, 35-42.

42 B. G. Tweedy, Phytopathology, 1964, 55, 910.

43 S. J. Sabounchei, P. Shahriary, Y. Gholiee, S. Salehzadeh, H. R. Khavasi and A. Chehregani, Inorg. Chim. Acta, 2014, 409(Part B), 265-275.

44 C. Shiju, D. Arish, N. Bhuvanesh and S. Kumaresan, Spectrochim. Acta, Part A, 2015, 145, 213-222.

45 S. C. Karad, V. B. Purohit, R. P. Thummar, B. K. Vaghasiya, R. D. Kamani, P. Thakor, V. R. Thakkar, S. S. Thakkar, A. Ray and D. K. Raval, Eur. J. Med. Chem., 2017, 126, 894-909.
46 M. Monajjemi and F. Mollaamin, J. Cluster Sci., 2012, 23, 259-272.

47 J. Liu, W. Zheng, S. Shi, C. Tan, J. Chen, K. Zheng and L. Ji, J. Inorg. Biochem., 2008, 102, 193-202.

48 C. N. N'Soukpoé-Kossi, C. Descôteaux, É. Asselin, H.-A. Tajmir-Riahi and G. Bérubé, DNA Cell Biol., 2007, 27, 101-107.

49 H. Soori, A. Rabbani-Chadegani and J. Davoodi, Eur. J. Med. Chem., 2015, 89, 844-850.

50 D. K. V. Kettamann and H. D. Holtje, J. Comput.-Aided Mol. Des., 2004, 18, 785.

51 T. Afrati, A. A. Pantazaki, C. Dendrinou-Samara, C. Raptopoulou, A. Terzis and D. P. Kessissoglou, Dalton Trans., 2010, 39, 765-775.

52 M. Sirajuddin, S. Ali and A. Badshah, J. Photochem. Photobiol., B, 2013, 124, 1-19. 